\title{
Empirical Findings on Motor Insurance Pricing in Germany, Austria, and Switzerland
}

\begin{abstract}
This paper focuses on recent developments in motor insurance pricing in Germany, Austria, and Switzerland. Through the analysis of responses to a recent comprehensive survey of industry representatives, we examine the various premium components and the processes involved in premium adaptation. New findings on the use of different tariff criteria, on the tools used for market-based and customer-specific pricing, and on the information considered for customer valuation are reported. We also address the integration of the insurance sales staff in the pricing process. With regard to premium adjustments and the introduction of new tariffs, we examine the frequency, time required, and costs incurred. With this paper, we contribute to a strand of literature where little academic research has been done so far. In addition, our results entail managerial implications for improving industry practices in insurance pricing.
\end{abstract}

Keywords insurance pricing $\cdot$ motor insurance $\cdot$ tariff criteria $\cdot$ customer valuation $\cdot$ pricing process

\section{Introduction}

One consequence of the deregulation of European insurance markets is an increase in competition among market players (see, e.g., Eling and Luhnen, 2008). In Germany in particular, motor insurance premiums have been under pressure in recent years, leading to combined ratios of around 100\% (see, e.g., Gesamtverband der Deutschen Versicherungswirtschaft, 2012). As competition between insurance companies intensifies, higher efficiency and greater focus on profitability are required. While the potential for cost reductions is limited, improvements in profitability and growth can be achieved through sophisticated pricing management mechanisms (see, e.g., Schmidt-Gallas and Lauszus, 2005, and Pratt, 2010).

In a recent survey by Hartmann et al. (2014), insurance industry practitioners in Germany, Austria, and Switzerland are asked about the current shape of the market and trends anticipated for coming years (see Hartmann et al., 2014, Figs. 47 and 48). With regard to the determination of the premium, experts make mention of increasing price differentiation according to individual risk profiles (T1) and based on alternative customer characteristics (T2). Furthermore, the average duration of customer relationships is expected to decrease (T3) and customers will be increasingly sensitive to price levels (T4). In the future, the market will also see heightened price competition (T5) and more rapid tariff adjustments (T6). The above trends signal challenges to the calculation of the various premium components and the processes for premium adjustments and the introduction of new tariffs.

For premium components, we distinguish between the traditional actuarial premium, cost loadings, adjustments for market conditions and the customer's profitability as well as any surcharges and discounts applied during the 
insurance distribution phase (see, e.g., Erdönmez et al., 2007, Fig. 4). Increased risk differentiation and the consideration of alternative risk characteristics (see trends T1 and T2 above) are posing challenges for actuarial pricing. Furthermore, shorter customer relationships and higher customer price sensitivity (T3 and T4) require improved customer-specific pricing based on the customer's value during the whole relationship and in all business lines. As a result of the more competitive landscape (T5), the use of market-specific surcharges and discounts must be effective and needs to be included in the premium models to ensure profitable underwriting. In our study, we will consider these different trends and present our findings with regard to risk-specific, customer-specific and market-based pricing. We also consider the integration of the insurance sales staff in price determination.

In a second batch of results, we illustrate our findings relating to pricing processes. In order to evaluate the ability of insurers to adjust tariffs more rapidly (T6), we analyze the frequency of pricing reviews and premium adjustments, the time needed and costs incurred for premium adjustments and the introduction of new tariffs.

The analyses in this paper focus on the three German speaking countries Germany, Austria, and Switzerland. This restriction arises from the used dataset and is necessary in order to ensure the comparability of data from different countries. For example, insurers in the three markets are subject to similar regulatory frameworks and have to comply with similar local GAAP standards.

The analyses in this paper are based on the same dataset and descriptive statistics as the study of Hartmann et al. (2014). However, their work is extended in several ways: First, while the study by Hartmann et al. (2014) mainly focuses on practitioners in the three German-speaking countries (and is therefore also written in German), our paper is more research oriented and takes into account numerous previous academic publications on motor insurance pricing. In this way we can provide a more comprehensive picture and several explanations for our findings. Second, in contrast to Hartmann et al. (2014), who attach great importance to the developments in pricing in recent years and compare a large part of their results with those of Erdönmez et al. (2007), we focus on the current state of motor insurance pricing and examine this aspect in greater details. Third, we do not restrict our analyses merely to descriptive evaluations of the survey (as done in Hartmann et al., 2014). Instead, we use several multivariate statistical methods such as linear and ordered logit regressions. As purely descriptive evaluations at country or firm-size level may lead to erratic conclusions (e.g., due to spurious correlations), our investigations permit a better identification of differences between firms of different sizes and in different countries. Moreover, various correlation analyses give a more comprehensive view of the usage and importance of tariff criteria, pricing tools, and customer information. Based on our findings, we also derive some practical implications, make suggestions for the design and implementation of the different fields of pricing, and provide several starting points for enhancements of the pricing processes. Finally, we also identify areas for future research.

In our paper we find a considerable backlog in the establishment of the non-traditional fields of pricing. As academic work is scarce in these areas (see the next section), our results emphasize the need for further. In addition, the usage of various tariff criteria in the field of actuarial pricing is analyzed from a new perspective, as motor insurers are directly asked for the importance of different tariff factors. Earlier papers, in contrast, mostly try to identify relevant tariff characteristics by means of analyses of premiums observed in the market. This procedure may lead to imprecise results as market premiums differ from the pure risk-based price. Practitioners may benefit from our analysis as they can identify possible shortcomings in their pricing processes and assess their performance in comparison to their competitors. Furthermore, we reveal substantial country-specific differences. The knowledge of these differences may be important if they consider expanding into another country. 
The remainder of this paper is structured as follows. Section 2 gives a short overview of the literature on motor insurance pricing. In Section 3, we explain our analysis methodology (questionnaire, data set, and statistical methods). In Section 4, we present and discuss the results of the study. Section 5 suggests several practical implications and Section 6 presents our conclusions.

\section{Literature Review}

\subsection{Academic Papers}

By far, most of the research has been done in the area of actuarial pricing. ${ }^{1}$ A substantial body of literature exists about the theory of risk classification, especially its effects on adverse selection, its profitability, costs, fairness, and efficiency (see, e.g., Doherty, 1981, Hoy, 1982, Abraham, 1985, Crocker and Snow, 1986). In this context, many articles also analyze the effects of regulatory restrictions on risk differentiation (see, e.g., Harrington and Doerpinghaus, 1993, Hoy, 2006, Thomas, 2007, Thomas, 2008). Moreover, a series of criteria for risk classification schemes and rating factors are formulated (see, e.g., Finger, 1996).

Numerous academic papers develop and analyze approaches for the selection of classification criteria and the calculation of the actuarial price. One of the predominant methods is the minimum-bias approach proposed by Bailey and Simon (1960) for multiplicative tariff models. This approach was further developed by Bailey (1963), Jung (1968), and Ajne (1975), among others, and is also a topic in current research (see, e.g., Ismail and Jemain, 2006). A second approach that attracted a great deal of attention is based on experience rating and credibility theory. The most famous credibility model was introduced by Bühlmann (1967) and Bühlmann and Straub (1970). This model, the estimation of its parameters, as well as possible enhancements were examined in a large number of subsequent papers, including Bichsel and Straub (1970), Sundt (1988), De Vylder and Goovaerts (1992), Dannenburg (1994), and Young and De Vylder (2000). A third category of models frequently proposed and analyzed for the modeling of motor insurance claims is that of (generalized) linear models (see, e.g., Baxter et al., 1980, and Stroinski and Currie, 1989). However, the three types of models are not mutually exclusive. Mildenhall (1999) and Nelder and Verrall (1997) show that generalized linear models can be related to the approach used by Bailey and Simon (1960) and Bailey (1963) as well as Bühlmann's credibility model. In addition, Ohlsson (2008) proposes a method that combines generalized linear models and the model discussed by Bühlmann and Straub (1970).

While the aforementioned papers mainly consider risk classifications and calculation methods in general, many articles from different research fields (actuarial science, transportation research, accident analysis) examine specific tariff criteria from different perspectives (e.g., predictive power, social acceptance, discrimination). For example, various analyses consider the driver's age (see, e.g., Kelly and Nielson, 2006, Brown et al., 2007, Oxera, 2012), the gender criterion (see, e.g., Oxera, 2010, and Schmeiser et al., 2014), or the vehicle's characteristics (see, e.g., Wenzel and Ross, 2005, and Kim et al., 2006). Furthermore, several authors investigate the effect of annual mileage on the frequency and severity of accidents, especially following the introduction of pay-as-you-drive tariffs (see, e.g., Janke, 1991, Litman, 2011, Boucher et al., 2013). The influence of driving behavior on crash risk is studied by Klauer et al. (2009), Paefgen et al. (2013b), and Ayuso et al. (2014), among others. Pefgen et al. (2013b) also develop an approach for the pricing of pay-how-you-drive tariffs. With regard to pay-how-you-drive tariffs, some analyses also focus on the effect of these tariff schemes on driving behavior (see, e.g., Bolderdijk et al., 2011, and Greaves et al., 2013).

\footnotetext{
${ }^{1}$ As there is an abundance of related academic papers, we focus on the main topics and some examples.
} 
In contrast to the field of actuarial pricing, the areas of customer-specific and market-based pricing and the integration of the sales channel are scarcely considered in the academic literature. ${ }^{2}$ An integrated model with three premium components is considered by Guelman et al. (2014). They suggest the use of personalized treatment models in order to determine pricing and select customers that should be addressed by a marketing strategy, such as price adjustments to increase cross-selling. Methods to identify profitable clients with cross-selling potential are also proposed by Thuring et al. (2012) and Kaishev et al. (2013). In addition, several papers deal with various aspects that are relevant for the customer specific component. These include the identification of influence factors on customer loyalty (see, e.g., Schlesinger and von der Schulenberg, 1993, and Brockett et al., 2008), and the development of methods for the prediction of the customer retention and its dependence on the premium level (see, e.g., Smith et al., 2000, Yeo et al., 2001, Guelman and Guillén, 2014). Moreover, Ryals and Knox, 2005, and Donkers et al, 2007, among others, focus on the estimation of the customer lifetime value and Verhoef and Donkers, 2001, consider the determination of the customer potential.

\subsection{Industrial Studies}

Besides the above mentioned academic papers, numerous studies aimed at practitioners in the insurance industry can be found. As it uses the same data set, the analysis with the closest link to our paper is the work of Hartmann et al. (2014). This is a follow-up study to the study by Erdönmez et al. (2007). The survey by Earnix (2011a) examines some similar aspects on pricing in the motor insurance sector (as well as other business lines), especially concerning the process for premium adjustments. However, its focus is on the European market. Analyses of the development of market-based and customer-specific pricing are, among others, provided by Schmidt-Gallas and Lauszus (2005) and Schmidt-Gallas and Beeck (2009). Moreover, Schmidt-Gallas and Beeck (2009) and Schmidt-Gallas et al. (2010) comprehensively describe current shortcomings and necessary improvements in the integration of the sales channel in Germany. Requirements for the pricing organization and pricing process are set out by Niessen (2013) and SchmidtGallas and Lauszus (2009b).

Furthermore, in recent years, numerous studies and consultative papers have been written that focus on usage-based pricing by means of telematics-based tariffs. A very comprehensive global study was published by Bruneteau et al. (2013). Other reports on telematics in motor insurance are written by Reddy (2012), Brat et al. (2013), and Jubraj et al. (2014), among others.

\section{Research Description}

\subsection{Description of the Questionnaire}

The questionnaire was developed by Hartmann et al. (2014) for their study on motor insurance pricing strategies. It is based on the questionnaire used for a similar survey (see Erdönmez et al., 2007), but comprises several new aspects. For the purpose of this paper, we focus on six question sets (labeled A to F).

\footnotetext{
${ }^{2}$ We focus on papers on pricing in insurance companies. In the general marketing literature, more research has been done. For a comprehensive article on the different components, see, e.g., Hinterhuber (2004).
} 


\section{Question Set A: Number of Customer Characteristics}

In order to determine the complexity of actuarial pricing, the companies are asked for the number of "collected" (A1) and "used" (A2) characteristics. While (A1) refers to the total number of characteristics collected on the policyholder, the vehicle, the drivers, etc. the insurers record in their database, (A2) only refers to those criteria that are actually used for rate determination. In the survey, the companies can choose any number between 1 and 50 .

\section{Question Set B: Impact of Tariff Criteria on Premium}

In this question set, survey participants are asked to assess the impact of different tariff criteria on the actuarial price. For each characteristic, the degree of impact is measured by means of a five-point Likert-type scale ranging from “very limited” to "very strong”. Following Meyer (2005), the tariff criteria are grouped into three categories: Items that describe the policyholder or the most frequent driver, characteristics of the insured vehicle, and information about the vehicle usage.

\section{Question Set C: Availability of Pricing Tools}

Question set C is designed to investigate the degree of development of the non-actuarial pricing components. For each component, the insurers are asked to state the availability of several tools that can support the decision process. Three answers can be chosen: "not available”, "partially available", and "available”. A tool is considered to be "partially available" if the firm has already started implementation, but cannot use it to its full extent.

\section{Question Set D: Information Used for Customer Valuation}

The aim of this question set is to get some further insights into the customer-specific pricing component by identifying the information the companies "use”, "partially use”, or "do not use” for the valuation of their customers. The question set includes 15 characteristics that describe the policyholder himself, the current relationship between the insurer and the customer, or the expected future relationship.

\section{Question Set E: Number of Pricing Revisions}

This is the first of two question sets to evaluate the process for premium adjustments. The insurers are asked to state how often they check the adequacy of their premiums (E1) and how many times prices are adjusted (E2). In both cases, five answers are possible: "once per year”, “2-3 times”, “4-6 times”, "more than 6 times” or "as required”.

\section{Question Set F: Time and Costs for New Premiums}

Question set F investigates the efforts associated with the introduction of new or modified premiums. First, participants are asked about the time (in days) needed for the adjustment of existing premium models (F1) and the introduction of new premium schemes (F2). Second, respondents are asked to give information about the costs (in person-days) resulting from premium adjustments (F3) and the introduction of new premium models (F4).

\subsection{Data Description}

The data were collected by Hartmann et al. (2014) between April and June 2013 in an online survey. In order to reach a high number of participating firms, the questionnaire was sent to 312 experts at 72 motor insurance companies in Ger- 
many, Austria, and Switzerland. ${ }^{3}$

The questionnaire was completed by 47 respondents from 31 different companies. In the analyses presented in this paper, we only include responses from insurance companies registered as such with the respective local regulatory authority. ${ }^{4}$ In cases where multiple responses were collected from the same company, the answer from the most senior motor pricing officer is selected. In this way we obtain a sample of 29 insurance companies - 9 from Germany, 8 from Austria, and 12 from Switzerland.

In order to identify possible response patterns for insurance companies of different sizes, we determine the gross written premiums (GWP) for the motor insurance business line. Using the statements of the local authorities, industry associations and the insurers' financial reports, we calculate the companies' 2012 premium volume in their motor liability and comprehensive cover business lines. ${ }^{5}$ Based on the premium figures, we derive their individual market shares in the motor insurance markets of their respective countries. Taking the median of the GWP (about EUR 275 million) as the critical value, we divide the companies into small and large motor insurers. Table 1 summarizes the market shares represented by the survey respondents in the three countries, divided into small and large insurers.

\begin{tabular}{l|ll|l}
\hline & Small & Large & Total \\
\hline Germany & 2.36 & 24.51 & 26.87 \\
Austria & 13.05 & 45.31 & 58.36 \\
Switzerland & 14.53 & 85.09 & 99.62 \\
\hline
\end{tabular}

Table 1: Market Shares of Survey Respondents

This table shows the market shares of survey respondents in the three countries as a percentage of total gross written premiums. The division into small and large insurers is based on the overall median of the GWP in the motor insurance line as the critical value.

\subsection{Statistical Methods}

The answers are evaluated both by means of descriptive analyses (see also Hartmann et al., 2014) and by various methods from multivariate data analysis. The latter allow the identification of possible differences with respect to the companies' size while controlling for the country and vice versa. However, due to the relatively small sample size, significance tests only have small power. In other words, the country or size effects are significant only when the differences between the subsamples are very large. If the tests do not show significant effects but the descriptive analysis indicates the existence of differences, the tests do not imply that there are no discrepancies. Instead, for our sample size the differences are not large enough to be declared "significant" with a small error probability.

\section{Ordinal and Nominal Scaled Variables}

With regard to the response variables with ordinal and nominal scale levels (i.e., the answers from question sets B to E), we consider the percentage distribution of answers across the different categories. The $95 \%$ - confidence interval for each proportion is calculated by means of the method proposed by Sison and Glaz (1995). In order to identify possible linkages between the ordered variables, we calculate Kendall’s rank correlation coefficient (Kendall, 1938, and Kendall, 1948). Finally, we estimate cumulative ordered logit models as specified in Agresti (2013).

\footnotetext{
${ }^{3}$ For an overview of the German, Austrian, and Swiss motor insurance markets see, e.g., Hartmann et al. (2014).

${ }^{4}$ It should be noted that companies acting as independent single players with independent pricing are included (e.g., the Swiss company smile.direct). We also take into consideration one respondent who completed the survey only partially.

${ }^{5}$ For currency conversions we apply the EUR / CHF exchange rate of 1.20773 as of December 31, 2012.
} 


\section{Interval Scaled Variables}

The interval scaled response variables resulting from question sets A and F are analyzed descriptively based on the mean, standard deviation, minimum, maximum, as well as the quantiles for the levels $0.25,0.5$, and $0.75 .{ }^{6}$ In addition, we determine Pearson's correlation coefficient for each pair of variables (see, e.g., Pearson, 1896). As Pearson's correlation coefficient only measures the linear dependence of bivariate normally distributed random variables, we also calculate Kendall's tau. Ordinary Least Square (OLS) regressions and ANOVA analyses (see, e.g., Miller, 1986) further permit the combined analysis of the country and size effects. However, the ANOVA significance tests require equal variances as well as normally distributed error terms (see, e.g., Miller, 1986, and Glass et al., 1972). According to Glass et al. (1972), especially heterogeneity may lead to substantial deviations from the intended type I error. The Levene test does not show significant deviations from variance homogeneity except for variable (F1). However, this insignificance might result from the small sample size.

The descriptive analysis results for the entire sample as well as the OLS results are summarized in Tables 2 to 10 in Section 4. For the results of the ordered logit regressions, we only show the significance of the country and size effects (*** indicates significance at the $1 \%$-level, ** significance at the $5 \%$-level, and * significance at the $10 \%$-level) in the main document (in the last columns of the descriptive tables). The detailed ordered logit results as well as the correlation tables are given in the Appendix in Tables A.1 and B.1 to B.3. ${ }^{7}$ The results of the descriptive analyses at country and size levels are not included in the paper and can be provided upon request by the authors.

\section{$4 \quad$ Results and Discussion}

\subsection{Actuarial Pricing}

\section{Number of Characteristics}

The actuarial price is determined based on a series of tariff criteria. Table 2 gives an overview of the amount of information collected and used by the survey participants. It shows that motor insurers in the three German-speaking countries collect an average of 24 characteristics (A1). However, as the answers range from 4 to 46 characteristics, there are large discrepancies between the companies. The mean number of tariff criteria (A2) amounts to 19 and is thus smaller than the average of (A1). With a minimum of 2 and a maximum of 40, the number of characteristics used for rating also varies considerably.

Our finding that insurers use less criteria for rating than they actually collect can be explained in several ways. For example, some information may be necessary for administrative purposes or captured in case it might be needed in the future. The latter could occur if some criteria are prohibited by the legal authorities, such as "gender" by the Unisex-directive in the European Union. Due to the correlation of various characteristics, if one criterion is forbidden, it may be replaced by other ones (for example gender by engine power, annual mileage and some other criteria, see Aseervatham et al., 2013)

\footnotetext{
${ }^{6}$ As the number of tariff criteria must be an integer, the empirical quantiles are calculated in the case of question set A. In contrast, a continuous quantile function is assumed for question set $\mathrm{F}$ (the quantile function of type 7 according to Hyndman and Fan, 1996).

${ }^{7}$ The McFadden R-squared and residual deviance in Table A.1 show that the country and size factor can only explain a low part of the variation in the response variables. As the ordered logit regressions are only complementary in order to disentangle the country and size effects, we do not deal with this issue.
} 


\begin{tabular}{llcccccccc}
\hline & Mean & St. dev. & Min & $\mathrm{Q}_{0.25}$ & $\mathrm{Q}_{0.50}$ & $\mathrm{Q}_{0.75}$ & Max & $\mathrm{C}$ \\
\hline (A1) & Collected characteristics & 24.29 & 11.56 & 4 & 14 & 24 & 34 & 46 & $*$ \\
(A2) & Used characteristics & 18.89 & 9.63 & 2 & 10 & 20 & 24 & 40 & $* * *$ \\
\hline
\end{tabular}

Table 2: Number of Customer Characteristics

\begin{abstract}
The values in the first seven columns of this table show the mean, standard deviation, minimum, $25 \% / 50 \% / 75 \%$ - quantile, and the maximum of the number of collected and used characteristics. The last column shows the significance of the country effect in the ANOVA regressions (the size effect is insignificant).
\end{abstract}

A country-specific analysis shows that German companies collect and use the highest amount of information. On average, they collect 29 characteristics and apply 26 tariff criteria for actuarial pricing. In Switzerland, somewhat fewer criteria are collected and used, on average (26 and 20, respectively). Austrian motor insurers rely on the lowest number of criteria, by far (17 and 9, respectively).

Comparing the descriptive statistics for the groups of small and large insurers indicates that companies with a large motor insurance portfolio tend to collect and use more information than their smaller competitors. On average, large companies collect (use) 7 (4) characteristics more than small motor insurance carriers.

The OLS regressions confirm the finding of the collection and use of a substantially lower number of characteristics in Austria than in Germany (see Table 3). The coefficients $\beta_{C H}$ and $\beta_{L}$ have the expected sign, but are not significant. With regard to the firm size, two conclusions are possible: On the one hand, the firm's size might in fact not have a significant influence and the observed differences in the means might result from the fact that the subsample of small companies comprises more Austrian and fewer German insurers than the subsample of large firms. On the other hand, the result might be attributed to the small power of the significance test and there could be differences with respect to the firm size nonetheless. As insurers with a small motor insurance portfolio have less data available for calibrating their tariffs it is very likely that they are less able to differentiate between their policyholders than large companies.

\begin{tabular}{lllllllll}
\hline & $\boldsymbol{\alpha}$ & $\boldsymbol{\beta}_{\boldsymbol{A U}}$ & $\boldsymbol{\beta}_{\boldsymbol{C H}}$ & $\boldsymbol{\beta}_{\boldsymbol{L}}$ & $\boldsymbol{F}_{\boldsymbol{C}}$ & $\boldsymbol{F}_{\boldsymbol{S}}$ & $\boldsymbol{F}_{\boldsymbol{C}+\boldsymbol{S}}$ & $\boldsymbol{R}^{2}$ \\
\hline (A1) & $26.00(4.16)^{* * *}$ & $-11.50(5.16)^{* *}$ & $-3.09(4.75)$ & $5.99(4.03)$ & $3.18^{*}$ & 2.14 & $2.86^{*}$ & 0.26 \\
(A2) & $24.17(2.98)^{* * *}$ & $-16.10(3.80)^{* * *}$ & $-5.67(3.39)$ & $2.49(2.91)$ & $9.49^{* * *}$ & 0.73 & $6.57^{* * *}$ & 0.46 \\
\hline
\end{tabular}

Table 3: OLS Results for the Number of Customer Characteristics

This table shows the OLS results for question set A. The estimated model is given by $y=\alpha+\beta_{A U} D_{A U}+\beta_{C H} D_{C H}+\beta_{L} D_{L}$ with dummy variables $D_{A U}, D_{C H}$, and $D_{L}$ for Austrian companies (AU), Swiss companies (CH), and large companies (L), respectively. The first three columns show the estimated coefficients, standard errors (in parentheses) and significance according to the t-test. Columns four to six display the test statistics of the F-tests for the significance of the country effect (C), the significance of the size effect (S), as well as the joint significance of all three variables $(\mathrm{C}+\mathrm{S})$, respectively. The asterisks illustrate the calculated significance levels. The last column displays the R-squared.

\title{
Impact of Different Tariff Criteria
}

Earlier papers on motor insurance pricing show that the impact of the tariff criteria used to determine the premium differs (see, e.g., Meyer, 2005, and Störmer and Wagner, 2013). As insurance companies in general do not disclose their actual rate calculations, this result is typically based on analyses of existing premiums in the market. Table 4 provides an overview of the influence of a series of tariff criteria when asking the companies directly.

With regard to the characteristics of the policyholder or most frequent driver, the driver's age, captured by (B1) and (B3), plays a key role at virtually all companies. Moreover, the place of residence (B4) has a moderate or strong impact in the majority of firms while the driver's family status (B5) seems to be of little importance. The impact of the date of driving license acquisition varies between the companies. 
The vehicle type or make (B6) turns out to be the most important criterion among the vehicle characteristics, followed by the date of first registration (B7) and power-to-weight ratio (B9). In contrast, the energy efficiency (B10) and method of financing (B11) have little or no impact on the premium for the majority of insurance firms.

The type of usage (B12) and the annual mileage (B13) seem to be the most influential criteria among those describing the vehicle usage. Nonetheless, they do not rank as high in importance as the driver's age, the vehicle type, and the registration date.

\begin{tabular}{|c|c|c|c|c|c|c|c|}
\hline & & 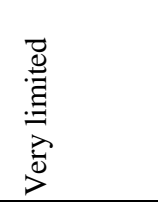 & 莒 & 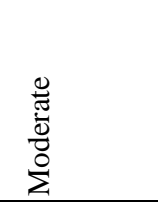 & 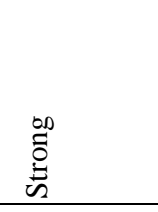 & $\begin{array}{l}0 \\
0 \\
0 \\
0 \\
\infty \\
0 \\
0 \\
0\end{array}$ & 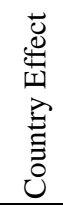 \\
\hline \multicolumn{8}{|c|}{ Policyholder / most frequent driver } \\
\hline (B1) & Age / date of birth & $3(0 ; 21)$ & $0 \quad(0 ; 18)$ & $3(0 ; 21)$ & $41(24 ; 59)$ & $52(34 ; 70)$ & \\
\hline (B2) & Date of driving license acquisition & $38(21 ; 56)$ & $10(0 ; 28)$ & $21(3 ; 38)$ & $21(3 ; 38)$ & $10(0 ; 28)$ & \\
\hline (B3) & Group of drivers / young people & $7 \quad(0 ; 27)$ & $3(0 ; 24)$ & $7 \quad(0 ; 27)$ & $28(14 ; 48)$ & $55(41 ; 76)$ & $*$ \\
\hline (B4) & Place of residence & $14(0 ; 32)$ & $7 \quad(0 ; 25)$ & $24(7 ; 42)$ & $41(24 ; 59)$ & $14(0 ; 32)$ & * \\
\hline (B5) & Family status / household composition & $48(31 ; 67)$ & $28(10 ; 46)$ & $21(3 ; 39)$ & $0 \quad(0 ; 19)$ & $3(0 ; 22)$ & \\
\hline \multicolumn{8}{|c|}{ Vehicle } \\
\hline (B6) & Make / type & $4(0 ; 22)$ & $4(0 ; 22)$ & $11(0 ; 29)$ & $43(25 ; 61)$ & $39(21 ; 58)$ & $* *$ \\
\hline (B7) & First registration & $3(0 ; 22)$ & $3(0 ; 22)$ & $38(21 ; 57)$ & $41(24 ; 60)$ & $14(0 ; 33)$ & * \\
\hline (B8) & Cubic capacity & $39(21 ; 58)$ & $7 \quad(0 ; 26)$ & $29(11 ; 47)$ & $21(4 ; 40)$ & $4(0 ; 22)$ & \\
\hline (B9) & Power-to-weight ratio & $28(10 ; 46)$ & $0 \quad(0 ; 19)$ & $21(3 ; 40)$ & $28(10 ; 46)$ & $24(7 ; 43)$ & $* * *$ \\
\hline (B10) & Energy efficiency & $59(45 ; 79)$ & $10(0 ; 30)$ & $28(14 ; 48)$ & $3(0 ; 24)$ & $0 \quad(0 ; 24)$ & \\
\hline (B11) & Method of financing & $41(24 ; 59)$ & $10(0 ; 35)$ & $21(3 ; 39)$ & $17(0 ; 35)$ & $3(0 ; 21)$ & $* * *$ \\
\hline \multicolumn{8}{|c|}{ Vehicle Usage } \\
\hline (B12) & Type of usage (private / business) & $28(10 ; 46)$ & $7(0 ; 25)$ & $28(10 ; 46)$ & $28(10 ; 46)$ & $10(0 ; 29)$ & $* *$ \\
\hline (B13) & Annual mileage & $10(0 ; 31)$ & $21(7 ; 41)$ & $28(14 ; 48)$ & $21(7 ; 41)$ & $21(7 ; 41)$ & $* * *$ \\
\hline (B14) & Driving behavior & $54(39 ; 74)$ & $11(0 ; 31)$ & $7(0 ; 28)$ & $21(7 ; 41)$ & $7 \quad(0 ; 28)$ & \\
\hline (B15) & Garage & $55(41 ; 75)$ & $21(7 ; 41)$ & $17(3 ; 38)$ & $7 \quad(0 ; 27)$ & $0 \quad(0 ; 20)$ & $*$ \\
\hline
\end{tabular}

Table 4: Impact of Tariff Criteria on Premium

The values in the first five columns of this table show the percentage distribution of answers across the five answer categories together with the calculated 95\% - confidence intervals (in parentheses). The asterisks in the last column indicate significance of the "country" factor in the ordered logit regressions (the "size" factor is insignificant).

There are several reasons for these differences in influence of different tariff criteria. One major cause is their varying predictive power with respect to future claims. Other aspects are the costs for their implementation or the possibility of being manipulated by the customer (see, e.g., Meyer, 2005, and Kelly and Nielson, 2006).

Furthermore, the results are to a large extent in line with the findings of previous papers. As indicated by the annual accident statistics (see, e.g., Statistisches Bundesamt, 2014) and shown, e.g., by Kelly and Nielson (2006) and Oxera (2012), there exists a strong U-shaped relationship between the driver's age and expected losses. While young drivers on average have larger claims as they have less driving experience and take more risks, older individuals are riskier drivers due to a deterioration of their cognitive and sensory skills (see, e.g., Kelly and Nielson, 2006, McKnight and McKnight, 1999, McKnight and McKnight, 2003). In addition, age is tied to a number of other useful 
characteristics (e.g., reliability over time, low implementation costs, objectivity) and is superior to several other rating criteria (see Kelly and Nielson, 2006).

The relatively high importance of the place of residence (B4) is in line with the high regional differences noted for motor insurance premiums (see, e.g., Köhne, 2011). Thus, motor insurers still heavily rely on regional classes for tariff schemes. The reason for this is that the frequency and severity of accidents differ substantially between places due to different traffic volume and road conditions (higher frequency in urban areas, worse consequences in rural regions, see, e.g., Etgar, 1975, and Sipulskyte, 2012).

The importance of the make and type of the vehicle can be explained in several ways. First, due to the differences in the vehicle prices, the repair and thus the claim costs differ (see Sipulskyte, 2012). Second, several papers show that the vehicle type influences the risk of a fatal accident and thus the severity of a crash (see, e.g., Kim et al., 2006, and Wenzel and Ross, 2005). Finally, as there is a strong relationship between the vehicle type and gender, the vehicle type can capture some of the gender effect (see ABI, 2010).

Concerning the annual mileage (B13), the moderate to strong impact can be explained as follows: As already indicated by Bailey and Simon (1960) and confirmed by a series of subsequent papers, the amount of annual claims and the frequency of claims increase with the driven distance (see, e.g., Litman, 2011, and Boucher et al., 2013). However, depending on the method of incorporating the annual mileage there can be a loss in accuracy, risk of manipulation or additional costs that reduce the benefits of this tariff criterion (see Abraham, 1985). Currently, most tariffs in the three countries only take the annual mileage as estimated by the customer into account. Moreover, instead of using the exact distance, drivers are classified only in a small number of broad classes. Thus there is a risk of misstatement by the policyholder (see White, 1976, and Abraham, 1985) and a loss in the predictive power. Telematics-based tariffs permit the use of the exact driven distance (see, e.g., Laurie, 2011). Moreover, it is possible to take the driving behavior into account (see, e.g., Laurie, 2011). However, the introduction of these tariffs poses several challenges (see e.g., Laurie, 2011, and Reddy, 2012) and telematics-based contracts are still scarce in the three considered countries (see Paefgen et al., 2013a, and Bruneteau et al., 2013). This also explains why the driving behavior, which cannot be measured without these techniques, has a substantial impact on motor insurance tariffs only in some companies, although the variable has a very high predictive power (see, e.g., Progressive, 2012, and Ayuso et al., 2014).

An analysis of the correlation of the characteristics' impact shows a significant correlation of 22 pairs of characteristics (out of a total of 105 pairs) (see Table B.1). Both criteria within one category (e.g., B1 and B3) and criteria of different categories (e.g., B1 and B5) are correlated. Moreover, while the remaining pairs (with significant results) are all positively related, the pairs (B6) and (B9), (B7) and (B9), as well as (B13) and (B9) correlate in a negative way. The negative rank correlation coefficient of the first two pairs can be attributed to the fact that the vehicle type (B6) and date of registration (B7) already imply a certain power-to-weight ratio (B9). This might also explain the low impact of (B9) in $28 \%$ of the participating companies, although the power-to-weight ratio significantly influences the probability and severity of an accident (see Kim et al., 2006).

While there seem to be only minor differences between companies of different sizes, the importance of numerous characteristics varies in the three countries. For example, the date of driving license acquisition (B2) has a strong or very strong impact in 50\% of Swiss motor insurers, but is hardly relevant for the majority of companies in the two EU countries. This criterion's relative importance in Switzerland can be explained by the deductible that Swiss motor insurers in general require from new drivers in the first two years after driving license acquisition. According to the ordered logit regressions, significant differences exist for (B3), (B4), (B6), (B7), (B9), (B11), (B12), (B13), and (B15). 


\subsection{Further Pricing Components}

\section{Pricing Tools}

The calculation of the actuarial price is only the first step in the determination of the final premium. In the next step, the price has to be adapted to market conditions, taking the company's strategy into account. Moreover, depending on the customer's willingness to pay and the value of the individual customer for the insurer, a customer-specific discount or surcharge has to be determined. The final price offered to the client is finally determined by the salesperson at the time of the sale of the product (see Erdönmez et al., 2007, and Hartmann et al., 2014).

The derivation of the market-based price, the customer-specific discount or surcharge as well as the influence of the sales staff have to be done in a professional, controlled way based on comprehensive analyses. Table 5 sums up the availability of various tools that can support and standardize the decision-making process. The results show that almost all insurers have set up instruments for market-based pricing (C1 to C3) and to integrate the sales channel (C8 to C10). However, in the majority of firms, the tools are implemented only partially and only around $30 \%$ are able to use them fully. With respect to instruments for customer-specific pricing only (C4) is widely implemented. The remaining tools (C5 to C7) exist and are developed to a lesser extent. This especially applies to instruments for pursuing a strategy based on the customer's value (C6) and taking into account the customer's potential (C7), which are unavailable in $43 \%$ and $46 \%$ of the companies, respectively. ${ }^{8}$

A calculation of Kendall's tau for each pair of tools indicates that the degree of availability of various tools within the same category (e.g., C6 and C7) is positively correlated (see Table B.2). Thus, instruments within a single category are not considered as interchangeable. In contrast, tools of different categories do not exhibit a significant non-zero correlation, implying that firms with many available instruments for market-based pricing have not necessarily developed (fully or partially) tools for customer-specific pricing or systematic integration of the sales channel.

Differentiating by country reveals that in German companies instruments (C5) to (C10) are fully implemented to a considerably lesser extent than in Swiss and Austrian insurance firms. Moreover, tools (C6), (C7), and (C10) are not even fully available in any of the participating companies from Germany. The ordered logit regressions do not show significant effects for the country effect. However, in recognition of the low power of the test and the discrepancies shown in the descriptive comparison, we consider it legitimate to conclude that German insurers have engaged less in the establishment of tools to integrate the customer's value and future potential.

A comparison of the answers of small and large motor insurers illustrates that tools for customer-specific pricing (C4 to C7) and the integration of the sales channel (C8 to C10) are not only available (partially or full) more often in firms with large motor insurance portfolios, their implementation is also much more likely to have been completed already. According to the results of the ordered logit regressions the differences with respect to the tools (C6) and (C9) are statistically significant. Thus, large insurers seem to have committed more to the development of these two steps for premium determination. On the one hand, this could imply that a majority of small companies still attach little value to these aspects. On the other hand, the result could stem from the fact that companies with a small motor insurance portfolio had to invest more in improving the calculation of the actuarial price and therefore had limited resources remaining for the other pricing components (see also Hartmann et al., 2014).

\footnotetext{
${ }^{8}$ The result of the need for further development in the three areas of pricing is confirmed by the essay of Gard and Eyal (2012), who state that $75 \%$ of companies are still focused on cost-based pricing (as indicated to us by one of this study's authors, this percentage is an estimate based on their experience in the P\&C markets of Germany, France, Italy, Spain, and the United Kingdom).
} 


\begin{tabular}{llll}
\hline & & & \\
\end{tabular}

Table 5: Availability of Pricing Tools

\begin{abstract}
This table shows the percentage distribution of answers across the three answer categories. The 95\% confidence intervals are given in parentheses. The asterisks in the last column indicate the significance of the size effect according to the ordered logit regressions (the country effect is insignificant).
\end{abstract}

There are several reasons for these backlogs in the fields of market-based and customer-specific pricing. First, insurance carriers have only gradually begun to attach importance to these components in recent years and it will take some time before they get established in companies where actuarial pricing has played a predominant role for decades. Second, they may face problems in obtaining appropriate market and customer data. Third, there may be difficulties in estimating adequate market-induced adjustments and the customer's profitability. These last two points are supported by the results of the survey by Earnix (2011a) among European non-life insurers. Some 40\% of this survey's respondents consider the collection and use of competitive data, the collection and use of customer data, and anticipating the customer's behavior as the main challenges in pricing.

\title{
Information for Customer Valuation
}

The previous analysis shows that the field of customer-specific pricing is still underdeveloped in many companies. To get deeper insights, Table 6 provides an overview of the information used for customer valuation. The results indicate that the four personal characteristics (D1) to (D4) are taken into account in the majority of firms. However, frequently the information is included only partially. In contrast, most elements that describe the current relationship between the insurer and the customer are fully accounted for in a large proportion of the companies. Especially the customer's claims history (D6) is considered as essential, as it is used to the full extent by almost every motor insurer. The indicators about the development of the relationship in the future (D13) to (D15) are used less often and to a lesser extent. 


\begin{tabular}{|c|c|c|c|c|c|c|}
\hline & & $\begin{array}{l}\text { ర્口 } \\
\cong \\
\Xi \\
0 \\
\text { 乙 }\end{array}$ & 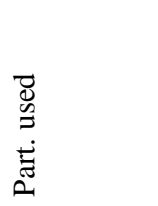 & $\begin{array}{l}\vec{D} \\
\mathscr{D}\end{array}$ & 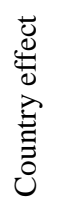 & 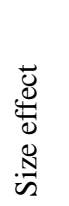 \\
\hline \multicolumn{7}{|c|}{ Personal characteristics } \\
\hline (D1) & Age / phase of life & $25(7 ; 45)$ & $43(25 ; 63)$ & $32(14 ; 52)$ & $*$ & $* *$ \\
\hline (D2) & Family status / household composition & $21(4 ; 40)$ & $50(32 ; 68)$ & $29(11 ; 47)$ & & \\
\hline (D3) & Geographic information & $29(11 ; 49)$ & $32(14 ; 52)$ & $39(21 ; 59)$ & & \\
\hline (D4) & Financial potential / creditworthiness & $32(14 ; 51)$ & $46(29 ; 66)$ & $21(4 ; 41)$ & & \\
\hline \multicolumn{7}{|c|}{ Current relationship } \\
\hline (D5) & Total premium volume & $4(0 ; 20)$ & $18(7 ; 34)$ & $79(68 ; 95)$ & $*$ & \\
\hline (D6) & Claims history & $0(0 ; 11)$ & $7(4 ; 18)$ & $93(89 ; 100)$ & & \\
\hline (D7) & Customer profitability & $0 \quad(0 ; 17)$ & $29(14 ; 45)$ & $71(57 ; 88)$ & $* *$ & \\
\hline (D8) & Duration of the relationship & $11(0 ; 31)$ & $29(14 ; 49)$ & $61(46 ; 81)$ & & \\
\hline (D9) & Number of products in the same line & $18(4 ; 39)$ & $29(14 ; 50)$ & $54(39 ; 75)$ & & \\
\hline (D10) & Number of products in other lines & $7(0 ; 23)$ & $21(7 ; 38)$ & $71(57 ; 88)$ & & \\
\hline (D11) & Last product purchase & $71(57 ; 88)$ & $21(7 ; 38)$ & $7 \quad(0 ; 23)$ & & $* *$ \\
\hline (D12) & Payment history & $14(0 ; 33)$ & $39(21 ; 58)$ & $46(29 ; 65)$ & & \\
\hline \multicolumn{7}{|c|}{ Future relationship } \\
\hline (D13) & Cross-selling potential & $21(4 ; 41)$ & $46(29 ; 66)$ & $32(14 ; 51)$ & & \\
\hline (D14) & Loss expectancy & $26(7 ; 45)$ & $30(11 ; 49)$ & $44(26 ; 64)$ & & \\
\hline (D15) & Lapse probability & $41(22 ; 60)$ & $33(15 ; 53)$ & $26(7 ; 45)$ & & $* * *$ \\
\hline
\end{tabular}

Table 6: Use of Different Information for Customer Valuation

The columns in this table show the percentage distribution of answers across the three response categories (together with the $95 \%$ confidence intervals in parentheses), as well as the significance of the country and size differences according to the ordered logit regressions.

A correlation analysis by means of Kendall's tau shows that within each of the three categories various characteristics are positively correlated (see Table B.3). This is in line with the expectation that carriers attaching importance to one category (e.g., personal characteristics) do not only select one element of this class. Moreover, if they are able to calculate one of the advanced measures of the last class (D13 to D15) they are also able to determine other ones.

The focus on information that describes the current relationship implies that many companies measure the customer's value only through the use of backward-looking, static metrics, such as the Past Customer Value (see, e.g., Kumar, 2007). A drawback of this procedure is that the policyholder's future purchase behavior is not taken into account. Instead, it is assumed that the past value of relationship is a good proxy for the customer's future profitability (see, e.g., Kumar, 2007). Moreover, the segmentation of new customers is not possible with these metrics.

Differentiating between countries indicates that most information (D1 to D3, D5 to D9, D11, D13, D14) is fully used to a greater extent by Austrian companies compared to German and Swiss insurers. Particularly striking is the information about the customer's profitability (D7) which is fully used by all participating companies from Austria, but only in half and two-thirds of the German and Swiss insurance firms, respectively. A similar picture emerges for the total premium 
volume (D5). In contrast, the characteristics (D4) and (D15) are used more in Germany than in Austria.

The results further confirm the previous finding of a claim-oriented focus of small carriers and a higher relevance of the customer's potential in large firms. While large companies account for the customer's cross-selling potential (D13) and lapse probability (D15) to a considerably higher extent than small firms, small motor insurers make greater use of the loss expectancy (D14). Companies with a high volume of motor insurance business also consider the customer's age (D1) and family status (D2), which also give some information concerning his future needs, to a larger extent. Notwithstanding this fact, there is also certain backlog among several large carriers.

Ordered logit regressions support the existence of large country-specific differences for the characteristics (D1), (D5), and (D7). Size has a significant influence for the characteristics (D1), (D11), and (D15). However, the results do not exclude the possibility of differences for the remaining variables.

\title{
4.3 Premium Adjustments and the Introduction of New Premiums
}

\section{Frequency of Reviews and Adjustments}

In a competitive market environment, companies must be able to revise and adjust their pricing frequently, within a short period of time, and at low cost. Table 7 displays the frequency of insurance firms' pricing reviews and adjustments. As can be seen from the first row, a large proportion of the companies $(40 \%)$ check pricing two or three times a year. A further $28 \%$ make revisions only once a year and $20 \%$ when required. With regard to the frequency of adjustments (E2), the companies' answers show that some of the firms with more reviews per year adapt their pricing less often. Consequently, the majority (56\%) adjust premiums only on a yearly basis. The remaining firms are more flexible, as they can change their pricing two or three times or when modifications are necessary.

\begin{tabular}{|c|c|c|c|c|c|c|c|c|c|}
\hline & & 1 & $2-3$ & & $4-6$ & & $>6$ & $\begin{array}{c}\text { As } \\
\text { required }\end{array}$ & $\begin{array}{c}\text { Country } \\
\text { effect }\end{array}$ \\
\hline (E1) & Reviews per year & $28(12 ; 50)$ & $40(24 ; 62)$ & 8 & $(0 ; 30)$ & 4 & $(0 ; 26)$ & $20(4 ; 42)$ & $*$ \\
\hline (E2) & Adjustments per year & $56(40 ; 78)$ & $20(4 ; 42)$ & 0 & $(0 ; 22)$ & 0 & $(0 ; 22)$ & $24(8 ; 46)$ & ** \\
\hline
\end{tabular}

Table 7: Number of Pricing Revisions

\begin{abstract}
This table shows the percentage distribution of answers across the five categories. The 95\%-confidence intervals are given in parentheses. The last column indicates the significance of the country effect in the ordered logit regressions for the first four categories (the "size" factor is insignificant).
\end{abstract}

A country-specific examination shows considerable differences in the dynamics between companies from different countries. While in Germany nearly $60 \%$ of motor insurers revise pricing only once a year, all Swiss companies check motor insurance premiums at least two times or when reviews seem necessary. Austrian insurers also predominantly check pricing more than once a year or as required. However, in contrast to their competitors in Switzerland, they are not able to make use of the frequent reviews and nearly all (88\%) adjust pricing only on a yearly basis. Seventy percent of German motor insurance companies also make adjustments not more than once a year and thus can react to new market conditions only with certain delay.

Splitting the answers according to the firm size gives similar results for both subsamples with respect to the frequency of reviews (E1). In contrast, the number of adjustments (E2) differs considerably, as $71 \%$ of small motor insurers but only $36 \%$ of large companies adapt prices only once a year. 
Ordered logit regressions for the subsample of companies with a specific number of reviews or adjustments confirm the existence of significant country-specific differences for both (E1) and (E2). In contrast, the size effect is not significant. Given the large differences between small and large insurers shown by the descriptive analysis of (E2), the result could be attributed to the low power of the significance test. However, in this case, it is more likely that there are indeed no substantial discrepancies and that the observed differences for (E2) are the result of the large proportion of Austrian and German companies (82\%) among small insurers (in the considered subsample).

There may be several reasons for a low number of reviews or adjustments. For example, the frequency of reviews is limited by the availability of necessary performance figures such as sales quota, cost ratios, and profitability estimates (see Niessen, 2013). Possible explanations for a small number of adjustments are infrequent reviews, IT restrictions (see Niessen, 2013), lack of data, manpower shortage, high costs or high time requirements. The latter will be analyzed in the next section.

\section{Efforts for Premium Adjustments and the Introduction of New Tariffs}

Table 8 gives an overview of the time and costs for premium adjustments and the introduction of new tariff models. The descriptive statistics show that the efforts associated with new premiums vary considerably between the companies. While the fastest insurer is able to adapt the premiums within 10 days, the slowest one needs more than six months. Half of the companies can make adjustments of existing tariffs within one month and can thus react to changing market conditions relatively quickly. As expected, the introduction of a new tariff requires more time than a simple adjustment. On average, the companies need 138 days, which is more than twice the mean time for premium adjustments (63 days). Half of the companies implement new premiums within four months or less and consequently have a clear advantage compared to the remaining insurers, some of which need more than half a year (provided that fast insurers are able to achieve the same level of accuracy of premiums as those that invest more time). ${ }^{9}$

\begin{tabular}{lccccccccc}
\hline & Mean & St. dev. & Min & $\mathrm{Q}_{0.25}$ & $\mathrm{Q}_{0.50}$ & $\mathrm{Q}_{0.75}$ & Max & $\mathrm{C}$ & $\mathrm{S}$ \\
\hline $\begin{array}{l}\text { Time (in days) } \\
\text { (F1) Premium adjustments }\end{array}$ & 62.76 & 53.91 & 10 & 30 & 30 & 100 & 200 & $* *$ & \\
(F2) Premium introduction & 138.28 & 77.19 & 10 & 70 & 130 & 200 & 300 & & \\
Costs (in person-days) & & & & & & & & & \\
(F3) Premium adjustments & 101.92 & 79.35 & 50 & 50 & 50 & 100 & 300 & $* *$ & $* *$ \\
(F4) Premium introduction & 351.85 & 273.33 & 50 & 125 & 300 & 500 & 1000 & $*$ & \\
\hline
\end{tabular}

Table 8: Time and Costs for New or Modified Premiums

The first five columns of this table show the mean, standard deviation, minimum, 25\%/50\%/75\%-quantile, and the maximum of the time and costs for tariff adjustments and introductions. Columns 6 and 7 display the significance of the country and size effects.

The cost for premium adjustments ranges from 50 to 300 person-days. One remarkable result is that $50 \%$ of the participants state that they have costs of 50 person-days. In accordance with the results for the duration, in most companies the cost for introducing new tariffs exceeds that for premium adjustments. Moreover, the differences between the firms are substantial: The maximum of the costs (1,000 person-days) is more than three times the median

\footnotetext{
${ }^{9}$ The finding of large differences is in line with the results of the survey by Earnix (2011a). In this survey, European insurance carriers were asked for the time needed to implement a new pricing strategy and the answers ranged from "less than two days" to "over three months".
} 
(300 person-days) and 20 times the minimum (50 person-days).

The calculation of Kendall's tau and the Pearson correlation coefficient shows that both the time and costs for premium adjustments (F1 and F3) and the time and costs for the introduction of new tariffs (F2 and F4) are highly positively correlated (see Table 9). Thus, motor insurers needing more time for the implementation of premium adjustments or new tariffs also tend to have higher financial efforts. In other words, companies with low time requirements are not more efficient because they employ more staff, but due to the availability of better processes (see Hartmann et al., 2014). Moreover, the times required for premium adjustments and the introduction of new tariffs (F1 and F2) are positively related, as well as the costs for both measures (F3 and F4). Consequently, carriers devoting greater resources for the modification of existing tariffs also tend to have greater cost and time expenditure for the introduction of new ones.

\begin{tabular}{lll}
\hline & Kendall & Pearson \\
\hline (F1), (F3) & $0.65^{* * *}$ & $0.75^{* * *}$ \\
(F2), (F4) & $0.56^{* * *}$ & $0.73^{* * *}$ \\
(F1), (F2) & $0.31^{* *}$ & $0.49^{* * *}$ \\
(F3), (F4) & $0.36^{* *}$ & 0.31 \\
\hline
\end{tabular}

Table 9: Correlation between Time and Costs for New or Modified Premiums

This table shows the Kendall and Pearson correlation coefficients for different pairs formed from these measures (F1) to (F4).

Furthermore, the results show that the efforts differ substantially both within and between the three countries. For example, the German subsample contains not only the slowest insurer, but also one of the companies with the lowest time for premium adjustments. With regard to the discrepancies between the three markets, the OLS regressions reveal that Swiss insurers need significantly lower time for premium adjustments (F1) and have significantly lower costs for tariff adjustments and introductions (F3 and F4) than German companies (see Table 10). The time requirements for new tariff schemes (F2) tend to be lower in Switzerland than in Germany, too, but the estimated effect is not significant. Austrian motor insurers also have significantly lower efforts for tariff adjustments (F1 and F3) than their German competitors. For the introduction of new premium systems, the results are not unique and the differences not significant. In addition, a comparison of the estimated coefficients $\beta_{A U}$ and $\beta_{C H}$ indicates that Swiss firms have the most time- and cost-efficient processes (for (F1), $\beta_{A U}$ is more negative than $\beta_{C H}$, but the difference is rather small).

\begin{tabular}{|c|c|c|c|c|c|c|c|c|}
\hline & $\alpha$ & $\boldsymbol{\beta}_{A U}$ & $\boldsymbol{\beta}_{C H}$ & $\boldsymbol{\beta}_{L}$ & $\boldsymbol{F}_{C}$ & $F_{S}$ & $\boldsymbol{F}_{C+S}$ & $R^{2}$ \\
\hline (F1) & $90.02(19.27)^{* * *}$ & $-59.26(24.04)^{* *}$ & $-47.34(21.63)^{* *}$ & 17.96 (18.39) & $3.97 * *$ & 0.95 & $2.96 *$ & 0.26 \\
\hline (F2) & $163.15(30.47)^{* * *}$ & $-30.27(38.02)$ & $-54.32(34.21)$ & 12.33 (29.09) & 1.30 & 0.18 & 0.92 & 0.10 \\
\hline (F3) & $122.76(26.41)^{* * *}$ & $-65.75(33.82)^{*}$ & $-86.57(30.34)^{* * *}$ & $66.99(25.71)^{* *}$ & $4.09 * *$ & $6.79 * *$ & $4.99 * * *$ & 0.40 \\
\hline (F4) & $373.38(102.03)^{* * *}$ & $51.97(127.00)$ & $-227.42(117.56)^{*}$ & 115.75 (98.39) & $3.00 *$ & 1.38 & $2.46^{*}$ & 0.24 \\
\hline
\end{tabular}

Table 10: OLS Results for the Efforts of Tariff Adjustments and Introductions

This table shows the OLS results for question set F. The model is given by $y=\alpha+\beta_{A U} D_{A U}+\beta_{C H} D_{C H}+\beta_{L} D_{L}$ with dummy variables $D_{A U}, D_{C H}$, and $D_{L}$ for Austrian companies (AU), Swiss companies (CH), and large companies (L), respectively. The first three columns show the estimated coefficients, standard errors (in parentheses) and significance according to the $\mathrm{t}$ - test. Columns four to six display the test statistics of the ANOVA F - tests for the significance of the country effect (C), the significance of the size effect $(\mathrm{S})$, as well as the joint significance of all three variables $(\mathrm{C}+\mathrm{S})$, respectively. The asterisks indicate the significance levels. The last column displays the R-squared. 
For the firm size the results indicate that companies with a large motor insurance portfolio tend to have higher efforts than small motor insurers. However, the size effect is significant only for (F3) and there are also some large insurers with low efforts. If processes work well, premium adjustments or new tariffs can thus be implemented without great efforts even if the portfolio is very large.

According to the foregoing analysis, the strong discrepancies between the companies generally cannot be attributed to differences in the portfolio size. Moreover, lower time requirements cannot be explained by higher personnel capacities. As German companies tend to use more tariff criteria (see Section 4.1) and have the highest effort levels, the complexity of actuarial pricing could be another explanation for the required amount of time and costs. However, although Swiss motor insurers use considerably more characteristics than the companies in Austria, they are able to implement new tariffs at lower cost and within less time. Moreover, the correlations between the variables describing the efforts for premium adjustments and the introduction of new tariffs (F1 to F4) and the number of tariff criteria (A2) are not significantly different from zero. Consequently, the higher cost and time requirements in some insurance firms cannot predominantly be attributed to the complexity of the tariff scheme. Instead, other factors such as the company organization or the pricing process seem to be more critical. Moreover, bad data preparation and inadequate IT systems can induce substantial delays (see Earnix, 2011b, and Niessen, 2013).

\section{Practical Implications}

\subsection{Actuarial Pricing}

Our survey shows that the number of tariff criteria used for actuarial pricing differs considerably between motor insurers in the three German-speaking countries. While $25 \%$ only take 10 or fewer criteria into account, another $25 \%$ consider 24 or more tariff criteria. When designing a tariff scheme, insurance companies should be aware that both too many and too few tariff criteria may be suboptimal.

On the one hand, a more sophisticated risk differentiation can improve the accuracy of the estimate of future claims and thus reduce underwriting risks (see, e.g., Abraham, 1985, and Vaughan and Michael, 2012). Moreover, it can help to reduce adverse selection (see, e.g., Oxera, 2013, and Schmeiser et al., 2014). By achieving the highest level of sophistication, insurers can also gain a competitive advantage and attract low-risk clients (see, e.g., Vaughan and Michael, 2012, and Schmeiser et al., 2014).

On the other hand, the use of each criterion leads to additional costs (e.g., data collection, verification, computational burden) (see, e.g., Meyer, 2005, and Kelly and Nielson, 2006). Thus, the use of more criteria may not lead to a net benefit. Especially if the segmentation is already quite granular and the new criterion is highly correlated with the existing characteristics, the cost increase is likely to exceed the benefits. Paefgen et al. (2013b) further emphasize the trade-off between the degree of risk segmentation and the accuracy of the parameter estimation. Negative effects can also occur if the additional criteria are not accepted by the customers (see Störmer, 2013). According to Störmer (2013), certain driver characteristics in particular (e.g., occupation, marital status) and several new criteria that are currently not in use receive low acceptance.

In consequence, motor insurance companies should revise their tariff schemes to ensure that they use an adequate number of powerful tariff criteria. They should avoid competing merely to develop the "biggest model" (Khanna and Ward, 2014, p. 2; see also Vaughan and Michael, 2012) and before introducing a new criterion, they should analyze the increase in precision, the associated costs, and its acceptance by the customers. 
The current technological and social developments will also require substantial revisions of tariff systems over the coming years. In particular, the introduction of pay-how-you-drive tariffs requires a fundamental reform of the traditional tariff scheme and a reassessment of all tariff criteria. As shown in our study, characteristics of the driver (e.g., age) and vehicle (e.g., vehicle type) are currently the most important tariff criteria. In contrast, in a pay-how-youdrive (PHYD) tariff scheme, characteristics that describe the driving behavior (e.g., the way of speeding, breaking, and cornering, the day and time of driving) play the predominant role and the remaining criteria are only ancillary (see, e.g., Laurie, 2011). With regard to the high volume of driving-behavior related data, Paefgen et al. (2013b) propose an approach for selecting the strongest predictor variables and combining them to create a single rating factor. The fast declining costs for telematics systems and the eCall requirement entering into effect in October 2015 in the European Union for new vehicles encourage the use of PHYD tariffs (see, e.g., Laurie, 2011, and Reddy, 2012). Moreover, besides enhancing the predictability of future claims, PHYD tariffs have several benefits, including improvements in driving behavior (see, e.g., Greaves et al., 2013, and Bolderdijk et al., 2011). Nevertheless, due to the challenges associated with these tariff schemes, the potential of PHYD tariffs in Germany, Switzerland, and Austria is controversial (see, e.g., Surminski, 2014).

Furthermore, the traditional tariff system will be challenged by changing mobility behavior in Western countries (see also Jahn et al., 2014). As shown by several studies, people increasingly abstain from possessing their own car and instead use car-sharing, public transport or other transportation options (see, e.g., Allianz, 2013). Consequently, the number of private vehicle registrations is declining while the number of car-sharing users is increasing substantially (see, e.g., Allianz, 2013). ${ }^{10}$ For motor insurers, this implies that the number of insured privately owned cars will decrease while the number of car-sharing vehicles that need to be insured increases. As the motor insurance provider does not know the individual driver in the case of car-sharing, personal tariff criteria will therefore become less important.

\subsection{Further Pricing Components}

While motor insurers devote considerable efforts to the optimization of actuarial pricing, the development of the remaining premium components receives less attention. However, we assume the non-traditional pricing components to be critical for the company's success as well. Schmidt-Gallas and Lauszus (2005) consider a pure cost-based pricing approach even as a "gamble" (see Schmidt-Gallas and Lauszus, 2005, p. 13). As shown in our study, in particular the field of customer-specific pricing is still in its infancy in the majority of companies. Tools used to examine the future development of the relationship are fully available only in a small proportion of companies and the customer's value is mainly calculated on the basis of characteristics of the current relationship. However, the establishment of an advanced customer-specific pricing unit and the use of forward-looking metrics (e.g., the customer lifetime value, CLV) is critical for the long-term success of the company (see Khanna and Ward, 2014, and Schmidt-Gallas and Beeck, 2009). It permits a differentiation between more and less profitable customers and the attraction of clients with high crossselling potential by means of individual discounts. The latter is possible since, in contrast to other insurance lines, price is still a very important factor in the purchasing decision for motor insurance policies (see Ernst \& Young, 2012, and Naujoks et al., 2012). Once the customer is acquired, the company can win the policyholder's trust and loyalty by providing excellent customer-centric services. The customer's confidence and satisfaction can then help to sell more complex products such as life insurance policies (see Ernst \& Young, 2012, and Naujoks et al., 2012).

The first step in the development of a professional customer-specific pricing component is the establishment of a

\footnotetext{
${ }^{10}$ This report by Allianz (2013) shows an increase in the number of new vehicle registrations for Switzerland in 2012. One major reason for this increase is the strength of the Swiss franc compared to the euro (see, e.g., Simer, 2014). In 2013, the number of new vehicle registrations also declined in Switzerland (see Statista, 2014).
} 
comprehensive firm-wide database that contains all information helpful in the estimation of the customer's future profitability. For this, insurers must break down their product and functional silos (see, e.g., Ernst \& Young, 2013, and PWC Consumer Finance Group, 2009) and share all information that is obtained in each business line and via each interaction channel. As other insurance lines (especially the life sector) typically have more personal contact with the customer than motor insurance staff (see Bättig et al., 2010, and Naujoks et al., 2012), they may have valuable information about the policyholder's future needs and cross-selling potential. Naujoks et al. (2012) also recommend frequent interaction with policyholders. Moreover, data from aggregator websites and social networking sites can contain useful information about the customers' needs, purchase behavior, and brand affinity (see Khanna and Ward, 2014).

Based on these data, insurance providers have to estimate the value of the policyholder over the whole duration of the relationship (this may be challenging). The most common metric for this purpose is the CLV, i.e., the present value of all future net profits (see, e.g., Gupta et al., 2006). Various methods for the calculation of the CLV have been proposed (see, e.g., Gupta et al., 2006, and Kumar, 2007). Approaches for the determination of the CLV in the insurance industry are considered in Jackson (1989a,b,c) and Donkers et al. (2007). Moreover, Ryals and Knox (2005) propose a method for the calculation of a so-called risk-adjusted CLV. In addition, Guillén et al. (2008) and Kim and Kim (1999) suggest approaches for the estimation of important influence factors on the CLV (the customer's loyalty and a life insurance customer’s upselling potential, respectively).

Our study further shows that tools for systematizing and controlling the influence of the sales unit are not fully implemented in the majority of companies. Nevertheless, many motor insurers allow large deviations from the target price (see Schmidt-Gallas et al., 2010). In combination with wrong incentives through inadequate remuneration systems for the sales staff this leads to huge discounts that may not be justified by the customer's profitability for the company (see Schmidt-Gallas and Lauszus, 2009a, and Schmidt-Gallas et al., 2010). Moreover, large arbitrary discounts or surcharges make the considerable efforts in the foregoing steps of actuarial, market-based, and customer-specific pricing almost worthless and can lead to substantial revenue losses (see Schmidt-Gallas et al., 2010). Allowing large price deviations may therefore be counterproductive (see Niessen, 2013). Discount budgets (i.e., the limitation of the total sum of discounts within one year) help to control the overall amount of discounts, but do not resolve the problem of assigning the discounts to the "right" clients (see Schmidt-Gallas et al., 2010). As the size of the budgets is frequently calculated by means of past data, the overall volume of discounts may further be inadequate (see Schmidt-Gallas et al., 2010, and Wedekind, 2012).

Giving some leeway to the sales unit has several advantages, such as higher motivation of the staff, faster conclusion of contracts (no need to seek permission for the discount), more rapid reactions to competitors' offers, and a better knowledge of the customer's willingness to pay (see Dolan and Simon, 1996, and Schmidt-Gallas and Lauszus, 2009a). Therefore, the possibility for some price variations should be maintained (see also Schmidt-Gallas et al., 2010). However, substantial changes to the current system are necessary. These include the introduction of concrete criteria for granting discounts, a careful determination of the tolerated deviations in accordance with the salesperson's performance and position, as well as the control of the use and effectiveness of price deviations (see Schmidt-Gallas and Lauszus, 2009a, and Schmidt-Gallas et al., 2010). Furthermore, the agent's remuneration should not depend only on the volume of the contract but also on its profitability (see Schmidt-Gallas and Lauszus, 2009a). The sales staff should also be informed about the entire relationship between the insurer and the policyholder and integrate this knowledge into its decision (see Schmidt-Gallas and Lauszus, 2009a). This again shows the need for a firm-wide database. Finally, the interaction between the sales unit, product development, and other pricing units has to be intensified. Through their direct contact with the customer, sales agents frequently are more knowledgeable of the 
product features customers are willing to pay for. In this way, offering products with components the customer does not want to have can more effectively be avoided, as can the need for sales staff to sell a police at a too low price.

\subsection{Combination of the Pricing Components}

The CLV framework also provides a concept to integrate the four fields of pricing and to determine the premium that takes all four factors into account. A possible strategy to set premiums is as follows:

1. Determine the premium that maximizes the CLV (see, e.g., Venkatesan and Kumar, 2004) under the constraint that it does not exceed the customer's willingness to pay and the market premium.

2. Communicate this premium to the sales agent and allow the agent to deviate from the price by certain percentage under the constraint that the sum of all deviations is non-negative for all customers in the segment.

Obviously, this strategy accounts for the results of the area of market based pricing and integrates the sales staff in a controlled way. In addition, as the CLV is the present value of all future cash flows to the company (in particular premiums and investment results) minus the present value of the payouts (in particular claims and administration costs), the actuarial price is considered in this maximization via the payout part. Customer-specific pricing deals with the prediction of the development of the future relationship between the company and its (potential) customer and therefore tries to anticipate all future cash-flows. In addition, the customer's willingness to pay needs to be estimated - for instance by means of a conjoint analysis.

\subsection{Pricing Process}

Our analysis shows that the performance of insurers with respect to premium adjustments and the introduction of new tariffs differs considerably. On the one hand, some insurers review their pricing regularly and are able to make adjustments several times a year. On the other hand, a number of motor insurance carriers monitor and change prices only once a year and are thus less flexible in reacting to changing market conditions and undesirable developments (see Earnix, 2011b, and Niessen, 2013). This in turn may negatively affect their profitability and growth (see Earnix, 2011b). Furthermore, while some companies can change premiums and introduce new tariffs within a short period of time and at low cost, others have to devote substantial resources to do so. Provided that both groups achieve the same level of accuracy of premiums, the group of insurers with greater efforts has a considerable competitive disadvantage.

A precondition for the early identification of the need for pricing adjustments is the continuous verification of the adequacy of current rates. Therefore, providers with infrequent reviews need to integrate a more effective monitoring system within their pricing processes. This system must constantly provide information about the development of market prices, claims ratios, profits, sales quotas, and other figures of interest (see, e.g., Sheaf, 2008, and Niessen, 2013). Sheaf (2008) recommends a reporting of the results at least on a monthly basis.

As mentioned in Section 4.3, there may be several reasons behind the considerable efforts associated with premium adjustments and the introduction of new tariffs at some firms. Consequently, there is no single solution to this problem. One starting point is an improvement in the availability and quality of pricing resources. In particular, a highly qualified staff, structured data preparation, powerful IT infrastructure, and analytical tools are essential for more rapid premium adjustments and the faster introduction of new tariffs (see Earnix, 2011b, and Niessen, 2013). Better interaction between all stakeholders in the pricing process can also accelerate pricing decisions (see Earnix, 2011b), since all parties will have better access to information, duplication of work will be avoided, and consensus will be reached faster. In some firms, it may further be necessary to overhaul the pricing organization and to establish a new governance structure for decision-making powers and responsibilities (see Schmidt-Gallas and Lauszus, 2009b).

https://doi.org/10.1057/gpp.2015.30 


\section{Conclusion}

Motivated by several trends that will challenge the motor insurance sector in the next years, this paper provides an indepth analysis of motor insurance pricing in Germany, Austria, and Switzerland. Based on a survey among insurance carriers in the three German-speaking countries, the different fields of pricing as well as processes for premium adjustments and the introduction of new tariffs are examined. In addition, by means of country- and size-specific analyses and advanced statistical methods, we identify differences between companies from different countries and of different sizes. Finally, some proposals for improvements are described.

An analysis of the area of actuarial pricing shows that motor insurers still focus on traditional tariff criteria describing the driver and the vehicle. Alternative characteristics (see trend T1 in Section 1) tend only to be considered on an ancillary basis. Concerning the trend for increasing risk differentiation (T2), potential for enhancements exists especially for firms in Austria. However, as emphasized in Section 5.1, insurance providers should not pursue the goal of achieving the highest level of risk segmentation. Instead, we think they should use their resources to encourage the development of the remaining pricing components. As revealed by our study, many motor insurers are very slow to implement market-based and customer-specific pricing, and fast progress is necessary in order to cope with heightened competition and changing customer behavior (trends T3 to T5). Furthermore, the influence of the sales channel on premium determination has to be reorganized.

The processes for premium adjustments and the introduction of new tariffs also exhibit some shortcomings, especially in Germany, and to a lesser extent in Austria. As regular and fast adjustments are essential in a highly competitive market and the trend is moving towards faster adjustments (see trend T6), motor insurers need to quickly eliminate existing shortcomings. Very high combined ratios in Germany make it imperative for German firms in particular to reduce costs for tariff adjustments and the introduction of new premiums (see also Hartmann et al., 2014).

In our analyses we focus on a description of the current situation in motor insurance pricing in the three German speaking countries. Moreover, our suggestions and conclusions are based on the assumption that higher and more professional engagement in the non-traditional fields of pricing and improved processes of premium adjustments and introductions can increase a company's performance. This hypothesis can be explained in several ways and follows the reasoning in various studies (see, e.g., Schmidt-Gallas and Lauszus, 2005, Schmidt-Gallas and Lauszus, 2009a, Earnix 2011b). In order to verify this hypothesis, a further comprehensive examination is necessary. Such an analysis could be an interesting future research topic. In this context it could be tested if, for instance, companies that use more criteria for customer valuation possess significantly lower combined ratios compared to insurers using only very few criteria.

\section{References}

Abraham, K. S., 1985. Efficiency and Fairness in Insurance Risk Classification. Virginia Law Review, 71(3):403-451.

Agresti, A., 2013. Categorical Data Analysis. John Wiley \& Sons, Hoboken, New Jersey, 3rd edition.

Ajne, B., 1975. A Note on the Multiplicative Ratemaking Model. ASTIN Bulletin, 8(2):144-153.

Allianz, 2013. Inter-connectedness is Revolutionizing Mobility Habits, Allianz Risk Pulse.

Aseervatham, V., C. Lex, and M. Spindler, 2013. Pitfalls in the Implementation of Non-discriminatory Premiums - the Case of Unisex Tariffs in the German Automobile Insurance Market, University of Munich, Institute for Risk Management and Insurance, Working Paper.

Ayuso, M., M. Guillén, and A.M. Pérez-Marín, 2014. Time and Distance to First Accident and Driving Patterns of Young Drivers with Pay-as-you-drive Insurance. Accident Analysis and Prevention, 73: 125-131. 
Laas, D., Schmeiser, H. \& Wagner, J. Geneva Pap Risk Insur Issues Pract 41, 398-431 (2016).

Bailey, R. A., 1963. Insurance Rates with Minimum Bias. Proceedings of the Casualty Actuarial Society, L(93):4-11.

Bailey, R. A. and L. J. Simon, 1960. Two Studies in Automobile Insurance Ratemaking. ASTIN Bulletin, 1(4):192-217.

Bättig, V., B. Burr, A. Fürnthaler, H. Schmeiser, A. Schlieker, C. Stampfli, and A. Zeier, 2010. Insurance in 2015 Determining the Position, New Coordinates in the German-speaking Insurance Market. Institute of Insurance Economics of the University of St. Gallen and Accenture, St. Gallen / Zurich, Switzerland.

Baxter, L. A., S. M. Coutts, and G. A. F. Ross, 1980. Applications of Linear Models in Motor Insurance. Proceedings of the 21st International Congress of Actuaries, Zurich, pp. 11-29.

Bichsel, F. and E. Straub, 1970. Erfahrungstarifierung in der Kollektivkrankenversicherung, unpublished manuscript.

Bolderdijk, J. W., J. Knockaert, E. M. Steg, and E. T. Verhoef, 2011. Effects of Pay-as-you-drive Vehicle Insurance on Young Drivers' Speed Choice: Results of a Dutch Field Experiment. Accident Analysis and Prevention, 43(3):11811186.

Boucher, J.-P., A. M. Pérez-Marín, and M. Santolino, 2013. Pay-as-you-drive Insurance: The Effect of the Kilometers on the Risk of Accident. Anales del Instituto de Actuarios Espanoles, 19:135-154.

Brat, E., D. Corradi, O. Eyal, T. Hoying, and Y. Sasaki, 2013. Telematics: The Test for Insurers, bcg.perspectives.

Brockett, P. L., L. L. Golden, M. Guillén, J. P. Nielsen, J. Parner, and A. M. Pérez-Marín, 2008. Survival Analysis of a Household Portfolio of Insurance Policies: How Much Time Do You Have to Stop Total Customer Defection. The Journal of Risk and Insurance, 75(3):713-737.

Brown, R. L., D. Charters, S. Gunz, and N. Haddow, 2007. Colliding Interests: Age as an Automobile Insurance Rating Variable: Equitable Rate-making or Unfair Discrimination? Journal of Business Ethics, 72(2):103-114.

Bruneteau, F., T. Hallauer, M. Noël, and S. Tusa, 2013. Usage-based Insurance, Global Study, Catch up with the Telematics Revolution. Ptolemus Consulting Group, Brussels, Belgium.

Bühlmann, H., 1967. Experience Rating and Credibility. ASTIN Bulletin, 4(3):199-207.

Bühlmann, H. and E. Straub, 1970. Glaubwürdigkeit für Schadensätze. Mitteilungen der schweizerischen Vereinigung der Versicherungsmathematiker, 70:111-133.

Crocker, K. J. and A. Snow, 1986. The Efficiency Effects of Categorical Discrimination in the Insurance Industry. Journal of Political Economy, 94(2):321-344.

Dannenburg, D., 1994. Some Results on the Estimation of the Credibility Factor in the Classical Bühlmann Model. Insurance: Mathematics and Economics, 14(1):39-50.

De Vylder, F. and M. J. Goovaerts, 1992. Estimation of the Heterogeneity Parameter in the Bühlmann-Straub Credibility Theory Model. Insurance: Mathematics and Economics, 10(4):233-238.

Doherty, N., 1981. Is Rate Classification Profitable. The Journal of Risk and Insurance, 48(2):286-295.

Dolan, R. D. and H. Simon, 1996. Power Pricing: How Managing Price Transforms the Bottom Line. The Free Press, New York.

Donkers, B., P. C. Verhoef, and M. G. de Jong, 2007. Modeling CLV: A Test of Competing Models in the Insurance Industry. Quantitative Marketing and Economics, 5(2):163-190.

Earnix, 2011a. European General Insurance Pricing Survey. (N.p.).

Earnix, 2011b. The New Insurance Pricing Process: 6 Keys to Success. (N.p.).

Eling, M. and M. Luhnen, 2008. Understanding Price Competition in the German Motor Insurance Market. Zeitschrift für die gesamte Versicherungswissenschaft, 97(1):37-50. 
Laas, D., Schmeiser, H. \& Wagner, J. Geneva Pap Risk Insur Issues Pract 41, 398-431 (2016).

Erdönmez, M., M. Gerber, and C. Nützenadel, 2007. Pricing-Strategien in der Motorfahrzeug-Versicherung. Institute of Insurance Economics of the University of St. Gallen and Solution Providers, St. Gallen / Dübendorf, Switzerland.

Ernst \& Young, 2012. Voice of the Customer: Time for Insurers to Rethink their Relationships, Global Consumer Insurance Survey 2012, Europe. London, United Kingdom.

Ernst \& Young, 2013. The Journey toward Greater Customer Centricity. New York.

Etgar, M., 1975. Unfair Price Discrimination in P-L Insurance and the Reliance on Loss Ratios. The Journal of Risk and Insurance, 42(4):615-624.

Finger, R. J., 1996. Risk Classification. In Casualty Actuarial Society (editor), Foundations of Casualty Actuarial Science, pp. 233-282. Arlington, Virginia, 3rd edition.

Gard, J.-C. and O. Eyal, 2012. The Six Steps to Pricing Power in Insurance, bcg.perspectives.

Gesamtverband der Deutschen Versicherungswirtschaft, 2012. The German Insurance Industry, 2012 Yearbook. Berlin, Germany.

Glass, G. V., P. D. Peckham, and J. R. Sanders, 1972. Consequences of Failure to Meet Assumptions Underlying the Fixed Effects Analyses of Variance and Covariance. Review of Educational Research, 42(3):237-288.

Greaves, S., S. Fifer, and R. Ellison, 2013. Exploring Behavioral Responses of Motorists to Risk-based Charging Mechanisms. Transportation Research Record: Journal of the Transportation Research Board, 2386(1):52-61.

Guelman, L. and M. Guillén, 2014. A Causal Inference Approach to Measure Price Elasticity in Automobile Insurance. Expert Systems with Applications, 41(2):387-396.

Guelman, L., M. Guillén, and A.M. Pérez-Marín, 2014. A Survey of Personalized Treatment Models for Pricing Strategies in Insurance. Insurance: Mathematics and Economics, 58: 68-76.

Guillén, M., J. P. Nielsen, and A. M. Pérez-Marín, 2008. The Need to Monitor Customer Loyalty and Business Risk in the European Insurance Industry. The Geneva Papers on Risk and Insurance - Issues and Practice, 33(2):207-218.

Gupta, S., D. Hanssens, B. Hardie, W. Kahn, V. Kumar, N. Lin, N. Ravishanker, and S. Sriram, 2006. Modeling Customer Lifetime Value. Journal of Service Research, 9(2):139-155.

Harrington, S. E. and H. I. Doerpinghaus, 1993. The Economics and Politics of Automobile Insurance Rate Classification. The Journal of Risk and Insurance, 60(1):59-84.

Hartmann, M., D. Laas, C. Nützenadel, H. Schmeiser, and J. Wagner, 2014. Pricing-Strategien in der KfZVersicherung. Institute of Insurance Economics of the University of St. Gallen and Solution Providers Switzerland, St. Gallen / Dübendorf, Switzerland.

Hinterhuber, A., 2004. Towards Value-based Pricing - An Integrative Framework for Decision Making. Industrial Marketing Management, 33(8):765-778.

Hoy, M., 1982. Categorizing Risks in the Insurance Industry. The Quarterly Journal of Economics, 97(2):321-336.

Hoy, M., 2006. Risk Classification and Social Welfare. The Geneva Papers on Risk and Insurance - Issues and Practice, 31(2):245-269.

Hyndman, R. J. and Y. Fan, 1996. Sample Quantiles in Statistical Packages. The American Statistician, 50(4):361-365.

Ismail, N. and A. A. Jemain, 2006. A Comparison of Risk Classification Methods for Claim Severity Data. Journal of Modern Applied Statistical Methods, 5(2):513-528.

Jackson, D., 1989a. Determining a Customer’s Lifetime Value, Part 1. Direct Marketing, 51(11):60-62/123.

Jackson, D., 1989b. Determining a Customer’s Lifetime Value, Part 2. Direct Marketing, 52(1):24-32.

https://doi.org/10.1057/gpp.2015.30 
Laas, D., Schmeiser, H. \& Wagner, J. Geneva Pap Risk Insur Issues Pract 41, 398-431 (2016).

Jackson, D., 1989c. Determining a Customer’s Lifetime Value, Part 3. Direct Marketing, 52(4):28/30.

Jahn, H. C., Heyen, M., Wälder, J. (2014). Sein oder nicht sein - die Zukunft der Kfz-Versicherung, PWC Insurance Monitor 3.

Janke, M. A., 1991. Accidents, Annual Mileage and the Exaggeration of Risk. Accident Analysis and Prevention, 23(2-3):183-188.

Jubraj, P., A. Moneta, and V. Summerhayes, 2014. Insurance Telematics: A Game-changing Opportunity for the Industry, Accenture's Series The Digital Insurer.

Jung, J., 1968. On Automobile Insurance Ratemaking. ASTIN Bulletin, 5(1):41-48.

Kaishev, V. K., J. P. Nielsen, and F. Thuring, 2013. Optimal Customer Selection for Cross-selling of Financial Services Products. Expert Systems with Applications, 40(5):1748-1757.

Kelly, M. and N. Nielson, 2006. Age as a Variable in Insurance Pricing and Risk Classification. The Geneva Papers on Risk and Insurance - Issues and Practice, 31(2):212-232.

Kendall, M. G., 1938. A New Measure of Rank Correlation. Biometrika, 30(1/2):81-93.

Kendall, M. G., 1948. Rank Correlation Methods. Griffin, London, United Kingdom.

Khanna, A. and P. Ward, 2014. Time to Get Streetwise: Unlocking Value-based Pricing in Personal Lines Insurance, L.E.K. Consulting, Executive Insights XVI/22.

Kim, B.-D. and S.-O. Kim, 1999. Measuring Upselling Potential of Life Insurance Customers: Application of a Stochastic Frontier Model. Journal of Interactive Marketing, 13(4):2-9.

Kim, H. S., H. J. Kim, and B. Son, 2006. Factors Associated with Automobile Accidents and Survival. Accident Analysis and Prevention, 38(5):981-987.

Klauer, S. G., T. A. Dingus, V. L. Neale, J. D. Sudweeks, and D. J. Ramsey, 2009. Comparing Real-world Behaviors of Drivers with High versus Low Rates of Crashes and Near-crashes, National Highway Traffic Safety Administration, Report No. DOT HS 811091.

Köhne, T., 2011. Zur Preissituation im deutschen Kfz-Versicherungsmarkt, Studie im Auftrag der Direct Line Versicherung AG. (Available at: http://blog.directline.de/wp-content/uploads/Studie-Zur-Preissituation-im-deutschenKfz-Versicherungsmarkt.pdf, accessed August 26 ${ }^{\text {th }}$, 2014).

Kumar, V., 2007. Customer Lifetime Value - The Path to Profitability. Foundations and Trends in Marketing, 2(1): $1-96$.

Laurie, A., 2011. Telematics: The New Auto Insurance. Towers Watson Emphasis, 2011(1):20-25.

Litman, T., 2011. Distance-based Vehicle Insurance, Feasibility, Costs and Benefits, Victoria Transport Policy Institute, Technical Report.

McKnight, J. A. and S. A. McKnight, 1999. Multivariate Analysis of Age-related Driver Ability and Performance Deficits. Accident Analysis and Prevention, 31(5):445-454.

McKnight, J. A. and S. A. McKnight, 2003. Young Novice Drivers: Careless or Clueless? Accident Analysis and Prevention, 35(6):921-925.

Meyer, U., 2005. Final Report for the Project Car Insurance Tariffs, Part III, Motor Liability Insurance in Europe, Comparative Study of the Economic-statistical Situation.

Mildenhall, S., 1999. A Systematic Relationship between Minimum Bias and Generalized Linear Models. Proceedings of the Casualty Actuarial Society, LXXXVI(164):393-487. 
Laas, D., Schmeiser, H. \& Wagner, J. Geneva Pap Risk Insur Issues Pract 41, 398-431 (2016).

Miller, R. G. J., 1986. Beyond ANOVA, Basics of Applied Statistics. John Wiley \& Sons, New York.

Naujoks, H., D. Lubig, and A. Bernert, 2012. Was Versicherungskunden wirklich wollen. Bain \& Company, Munich, Germany.

Nelder, J. A. and R. J. Verrall, 1997. Credibility Theory and Generalized Linear Models. ASTIN Bulletin, 27(1):71-82.

Niessen, G., 2013. Tarifierung in den Nicht-Lebens-Sparten - Welche Informationen benötigt das Management. In J. Strobel (editor), Rechnungsgrundlagen und Prämien in der Personen- und Schadenversicherung - Aktuelle Ansätze, Möglichkeiten und Grenzen, pp. 20-43. Cologne, Germany.

Ohlsson, E., 2008. Combining Generalized Linear Models and Credibility Models in Practice. Scandinavian Actuarial Journal, 2008(4):301-314.

Oxera, 2010. The Use of Gender in Insurance Pricing, ABI Research Paper No. 24.

Oxera, 2012. Why the Use of Age and Disability Matters to Consumers and Insurers. Oxford, United Kingdom.

Oxera, 2013. Equality in Insurance Pricing: the Effect of the Gender Ban, Oxera Agenda April 2013.

Paefgen, J., E. Fleisch, L. Ackermann, T. Staake, J. Best, and L. Egli, 2013a. Telematics Strategy for Automobile Insurers, I-Lab Whitepaper.

Paefgen, J., T. Staake, and F. Thiesse, 2013b. Evaluation and Aggregation of Pay-as-you-drive Insurance Rate Factors: A Classification Analysis Approach. Decision Support Systems, 56:192-201.

Pearson, K., 1896. Mathematical Contributions to the Theory of Evolution. III. Regression, Heredity, and Panmixia. Philosophical Transactions of the Royal Society A: Mathematical, Physical and Engineering Sciences, 187:253-318.

Pratt, K., 2010. Pricing. The Journal of the Chartered Insurance Institute, 2010(February/March):19-21.

Progressive, 2012. Linking Driving Behavior to Automobile Accidents and Insurance Rates, An Analysis of Five Billion Miles Driven, Snapshot Report.

PWC Consumer Finance Group, 2009. Customer Segmentation: How to Harness its Profit-building Power. PricewaterhouseCoopers, Melbourne, Australia.

Reddy, A. S., 2012. The New Auto Insurance Ecosystem: Telematics, Mobility and the Connected Car, Cognizant Reports.

Ryals, L. J. and S. Knox, 2005. Measuring Risk-adjusted Customer Lifetime Value and its Impact on Relationship Marketing Strategies and Shareholder Value. European Journal of Marketing, 39(5/6):456-472.

Schlesinger, H. and J. M. von der Schulenberg, 1993. Consumer Information and Decisions to Switch Insurers. The Journal of Risk and Insurance, 60(4):591-615.

Schmeiser, H., T. Störmer, and J. Wagner, 2014. Unisex Insurance Pricing: Consumers' Perception and Market Implications. The Geneva Papers on Risk and Insurance - Issues and Practice, 39(2):322-350.

Schmidt-Gallas, D. and V. Beeck, 2009. Das Pricing deutscher Versicherer im internationalen Vergleich. Simon Kucher \& Partners, Frankfurt am Main, Germany.

Schmidt-Gallas, D., V. Beeck, and M. Paluch, 2010. Neue Rabattsysteme für eine konsistente Positionierung und mehr Ertrag. transfer Werbeforschung \& Praxis, 56(4):49-52.

Schmidt-Gallas, D. and D. Lauszus, 2005. Mehr Markt: Die Pricing-Prozesse der Versicherer müssen besser werden, Ergebnisse der Branchenbefragung 2005 und Empfehlungen für das Management. Simon Kucher \& Partners, Bonn, Germany.

Schmidt-Gallas, D. and D. Lauszus, 2009a. Die Wertschöpfung im Vertrieb steigern. Simon Kucher \& Partners, Bonn, 


\section{Germany.}

Schmidt-Gallas, D. and D. Lauszus, 2009b. Pricing-Exzellenz durch schlagkräftige Organisationen. Simon Kucher \& Partners, Bonn, Germany.

Sheaf, S., 2008. Insurance: Rate Monitoring Systems. The Actuary (Online article, available at: http://www.theactuary.com/, accessed September $\left.12^{\text {th }}, 2014\right)$.

Simer, A., 2014. Schweiz - Kfz-Industrie und Kfz-Teile. Bonn, Germany.

Sipulskyte, R., 2012. Development of a Motor Vehicle Classification Scheme for a New Zealand Based Insurance Company, New Zealand Society of Actuaries Conference 2012.

Sison, C.P. and J. Glaz, 1995. Simultaneous Confidence Intervals and Sample Size Determination for Multinomial Proportions. Journal of the American Statistical Association, 90(429):366-369.

Smith, K. A., R. J. Willis, and M. Brooks, 2000. An Analysis of Customer Retention and Insurance Claim Patterns Using Data Mining: A Case Study. The Journal of the Operational Research Society, 51(5):532- 541.

Statista, 2014. Anzahl der Neuzulassungen von Kraftfahrzeugen in der Schweiz in den Jahren 2005 bis 2013 nach Fahrzeuggruppe. (Online chart, available at: http://de.statista.com/, accessed September 19 ${ }^{\text {th }}$, 2014).

Statistisches Bundesamt, 2014. Verkehr: Verkehrsunfälle 2013. Wiesbaden, Germany.

Störmer, T., 2013. Optimizing Insurance Pricing by Incorporating Consumers' Perceptions of Risk Classification, University of St. Gallen, Institute of Insurance Economics, Working Papers on Risk Management and Insurance No. 140.

Störmer, T. and J. Wagner, 2013. A Comparison of Insurers' Usage and Consumers' Perception of Price Differentiation Factors, University of St. Gallen, Institute of Insurance Economics, Working Papers on Risk Management and Insurance No. 139.

Stroinski, K. J. and I. D. Currie, 1989. Selection of Variables for Automobile Insurance Rating. Insurance: Mathematics and Economics, 8(1):35-46.

Sundt, B., 1988. Credibility Estimators with Geometric Weights. Insurance: Mathematics and Economics, 7(2):113122.

Surminski, M., 2014. Gibt es ein Geschäftsmodell für Telematik-Tarife in Deutschland? Zeitschrift für Versicherungswesen, 2014(6):163-164.

Thomas, G. R., 2007. Some Novel Perspectives on Risk Classification. The Geneva Papers on Risk and Insurance Issues and Practice, 32(1):105-132.

Thomas, G. R., 2008. Loss Coverage as a Public Policy Objective for Risk Classification Schemes. The Journal of Risk and Insurance, 75(4):997-1018.

Thuring, F., J. Nielsen, M. Guillén, and C. Bolancé, 2012. Selecting Prospects for Cross-selling Financial Products Using Multivariate Credibility. Expert Systems with Applications, 39(10):8809-8816.

Vaughan, D. and L. Michael, 2012. Why Rate Differentiation is Important: Equal May Not Be Fair. Towers Watson Emphasis, 2012(2):2-5.

Venkatesan, R. and V. Kumar, 2004. A Customer Lifetime Value Framework for Customer Selection and Resource Allocation Strategy. Journal of Marketing, 68(4):106-125.

Verhoef, P. C. and B. Donkers, 2001. Predicting Customer Potential Value an Application in the Insurance Industry. Decision Support Systems, 32(2):189-199.

Wedekind, K., 2012. Profitable und unprofitable Kunden klassifizieren, Implementierung eines Kundenwert- 
managements im Versicherungsunternehmen. Versicherungswirtschaft, 2012(23):1726-1727.

Wenzel, T. P. and M. Ross, 2005. The Effects of Vehicle Model and Driver Behavior on Risk. Accident Analysis and Prevention, 37(3):479-494.

White, S. B., 1976. On the Use of Annual Vehicle Miles of Travel Estimates from Vehicle Owners. Accident Analysis and Prevention, 8(4):257-261.

Yeo, A. I., K. A. Smith, R. J. Willis, and M. Brooks, 2001. Modeling the Effect of Premium Changes on Motor Insurance Customer Retention Rates Using Neural Networks. Lecture Notes in Computer Science, 2074:390-399.

Young, V. R. and E. F. De Vylder, 2000. Credibility in Favor of Unlucky Insureds. North American Actuarial Journal, 4(1):107-113.

\section{Appendix}

\begin{tabular}{|c|c|c|c|c|c|c|c|c|}
\hline & $\gamma_{\mathrm{AU}}$ & $\gamma_{\mathrm{CH}}$ & $\gamma_{L}$ & $\mathbf{L R}_{\mathbf{C}}$ & $\mathbf{L R}_{\mathbf{S}}$ & $\mathbf{L R}_{\mathbf{C}+\mathbf{S}}$ & $\mathbf{D}_{\mathrm{R}}$ & $\mathbf{R}_{\text {MF }}^{2}$ \\
\hline (B3) & $-2.19(1.26)^{*}$ & $-2.31(1.21)^{*}$ & $0.89(0.78)$ & $5.30 *$ & 1.35 & $6.96 *$ & $60.80^{* * *}$ & 0.10 \\
\hline (B4) & $-2.16(0.98)^{* *}$ & $-0.59(0.81)$ & $1.09(0.72)$ & $5.34 *$ & 2.35 & $7.86^{* *}$ & $75.61^{* * *}$ & 0.09 \\
\hline (B6) & $-2.54(1.17)^{* *}$ & $-2.32(1.02)^{* *}$ & $0.94(0.79)$ & $7.32 * *$ & 1.47 & $8.62 * *$ & $59.00 * * *$ & 0.13 \\
\hline (B7) & $-1.90(1.02)^{*}$ & $-1.88(0.89)^{* *}$ & $-0.65(0.72)$ & $5.79 *$ & 0.83 & $6.33^{*}$ & $65.49 * * *$ & 0.09 \\
\hline (B9) & $2.31(1.01)^{* *}$ & $2.59(0.92)^{* * *}$ & $0.47(0.70)$ & $9.90 * * *$ & 0.45 & $10.07^{* *}$ & $69.94 * * *$ & 0.13 \\
\hline (B11) & $0.15(0.95)$ & $2.52(0.96)^{* * *}$ & $-0.43(0.74)$ & $10.17^{* * *}$ & 0.33 & $10.17^{* *}$ & $71.80^{* * *}$ & 0.12 \\
\hline (B12) & $-1.88(0.98)^{*}$ & $-2.56(0.91)^{* * *}$ & $-0.84(0.74)$ & $9.04 * *$ & 1.30 & $9.34 * *$ & $76.79 * * *$ & 0.11 \\
\hline (B13) & -12.19 (35.78) & -11.49 (35.77) & $-0.20(0.71)$ & $28.00 * * *$ & 0.08 & $28.30 * * *$ & $62.64^{* * *}$ & 0.31 \\
\hline (B15) & $-2.11(1.24)^{*}$ & $0.36(0.82)$ & $0.16(0.76)$ & $5.76^{*}$ & 0.04 & 6.08 & $60.13^{* * *}$ & 0.09 \\
\hline (C6) & 1.51 (1.09) & $1.26(0.92)$ & $2.24(0.86)^{* * *}$ & 2.65 & $7.89 * * *$ & $9.10^{* *}$ & $50.31^{* * *}$ & 0.15 \\
\hline (C9) & $2.13(1.16)^{*}$ & $0.92(0.97)$ & $2.64(1.01)^{* * *}$ & 4.20 & $8.91^{* * *}$ & $11.33^{* *}$ & $42.19^{* * *}$ & 0.21 \\
\hline (D1) & $0.42(1.02)$ & $-1.52(0.95)$ & $1.52(0.79)^{*}$ & $5.40 *$ & $3.96 * *$ & $8.14^{* *}$ & $52.03 * * *$ & 0.14 \\
\hline (D5) & $8.30(27.23)$ & $0.74(0.99)$ & $0.17(0.98)$ & $5.23 *$ & 0.03 & 5.24 & 29.26 & 0.15 \\
\hline (D7) & $9.41(39.40)$ & $0.73(0.96)$ & $-0.87(0.95)$ & $6.83^{* *}$ & 0.86 & $8.00^{* *}$ & 25.50 & 0.24 \\
\hline (D11) & $1.91(1.31)$ & $0.038(1.13)$ & $2.48(1.14)^{* *}$ & 3.00 & $6.19 * *$ & $7.20^{*}$ & $35.30 * *$ & 0.17 \\
\hline (D15) & $-0.94(1.05)$ & $-1.43(1.00)$ & $2.55(0.90)^{* * *}$ & 2.15 & $9.77^{* * *}$ & $11.00^{* *}$ & $47.43^{* *}$ & 0.19 \\
\hline (E1) & $1.63(1.22)$ & $2.47(1.22)^{* *}$ & $0.17(0.94)$ & $4.84^{*}$ & 0.03 & 5.11 & $38.65^{* * *}$ & 0.12 \\
\hline (E2) & $-7.84(41.13)$ & $2.06(1.53)$ & $2.06(1.53)$ & $6.76^{* *}$ & 2.02 & $10.87^{* *}$ & 11.03 & 0.50 \\
\hline
\end{tabular}

Table A.1: Detailed Ordered Logit Results

This table shows the detailed results of the ordered logit regression for the response variables from question sets B, C, D, and E. Only variables with significant country or size differences are included. The estimated model is given by $\operatorname{logit}\left(P(Y \leq j)=\alpha_{j}-\gamma_{A U} D_{A U}-\gamma_{C H} D_{C H}-\gamma_{L} D_{L}\right.$. Here, $D_{A U}, D_{C H}$, and $D_{L}$ are dummy variables that indicate the existence of an Austrian company (AU), Swiss company (CH), and large company (L), respectively. The first three columns show the estimated coefficients, standard errors (in parentheses) and significance according to the Wald test. Columns four to six display the test statistics of the likelihood-ratio chi2-tests for the significance of the country effect (C), the significance of the size effect (S), as well as the joint significance of all three variables $(\mathrm{C}+\mathrm{S})$, respectively. The asterisks illustrate the calculated significance levels. $D_{R}$ in column seven corresponds to the residual deviance. Here, the asterisks indicate the p-value for the test of the null hypothesis that the fitted model explains the data pretty well (i.e., no asterisks indicate that the model can explain the whole variation in the data). The last column contains the McFadden R-squared. 
Laas, D., Schmeiser, H. \& Wagner, J. Geneva Pap Risk Insur Issues Pract 41, 398-431 (2016).

\begin{tabular}{|c|c|c|c|c|c|c|c|c|c|c|c|c|c|c|c|}
\hline & (B1) & (B2) & (B3) & (B4) & (B5) & (B6) & (B7) & (B8) & (B9) & (B10) & (B11) & (B12) & (B13) & (B14) & (B15) \\
\hline (B1) & 1.00 & 0.02 & $0.55^{* * *}$ & 0.26 & 0.15 & 0.07 & $0.5^{* * *}$ & -0.01 & 0.00 & -0.01 & 0.00 & 0.10 & 0.18 & -0.13 & 0.08 \\
\hline (B2) & 0.02 & 1.00 & 0.02 & -0.05 & $0.28^{*}$ & -0.1 & 0.07 & 0.09 & $0.28 *$ & -0.02 & 0.25 & 0.03 & -0.1 & 0.1 & 0.16 \\
\hline (B3) & $0.55^{* * *}$ & 0.02 & 1.00 & $0.46^{* * *}$ & 0.24 & 0.15 & $0.39 * *$ & 0.02 & -0.14 & -0.04 & 0.07 & 0.15 & $0.39 * *$ & -0.05 & 0.12 \\
\hline (B4) & 0.26 & -0.05 & $0.46 * * *$ & 1.00 & 0.01 & 0.05 & $0.32 *$ & 0.14 & -0.17 & -0.04 & 0.2 & 0.16 & $0.28 *$ & -0.12 & $0.35 * *$ \\
\hline (B5) & 0.15 & $0.28^{*}$ & 0.24 & 0.01 & 1.00 & 0.13 & 0.26 & -0.06 & 0.16 & 0.04 & 0.24 & 0.09 & 0.10 & 0.23 & 0.07 \\
\hline (B6) & 0.07 & -0.1 & 0.15 & 0.05 & 0.13 & 1.00 & $0.4^{* *}$ & -0.16 & $-0.33^{*}$ & -0.06 & -0.12 & 0.05 & $0.51^{* * *}$ & 0.05 & 0.18 \\
\hline (B7) & $0.5^{* * *}$ & 0.07 & $0.39 * *$ & $0.32 *$ & 0.26 & $0.4^{* *}$ & 1.00 & -0.13 & $-0.34 * *$ & -0.02 & 0.03 & 0.26 & $0.32 * *$ & -0.11 & 0.1 \\
\hline (B8) & -0.01 & 0.09 & 0.02 & 0.14 & -0.06 & -0.16 & -0.13 & 1.00 & 0.07 & 0.10 & -0.05 & $0.27^{*}$ & 0.16 & 0.23 & $0.5^{* * *}$ \\
\hline (B9) & 0.00 & $0.28^{*}$ & -0.14 & -0.17 & 0.16 & $-0.33 *$ & $-0.34^{* *}$ & 0.07 & 1.00 & 0.05 & $0.33^{* *}$ & -0.13 & $-0.36 * *$ & 0.22 & 0.04 \\
\hline (B10) & -0.01 & -0.02 & -0.04 & -0.04 & 0.04 & -0.06 & -0.02 & 0.1 & 0.05 & 1.00 & 0.23 & -0.12 & -0.01 & -0.13 & 0.1 \\
\hline (B11) & 0.00 & 0.25 & 0.07 & 0.2 & 0.24 & -0.12 & 0.03 & -0.05 & $0.33^{* *}$ & 0.23 & 1.00 & 0.00 & -0.18 & -0.02 & $0.33^{* *}$ \\
\hline (B12) & 0.10 & 0.03 & 0.15 & 0.16 & 0.09 & 0.05 & 0.26 & $0.27 *$ & -0.13 & -0.12 & 0.00 & 1.00 & $0.29 *$ & -0.18 & $0.33^{* *}$ \\
\hline (B13) & 0.18 & -0.10 & $0.39 * *$ & $0.28 *$ & 0.1 & $0.51^{* * *}$ & $0.32 * *$ & 0.16 & $-0.36^{* *}$ & -0.01 & -0.18 & $0.29 *$ & 1.00 & -0.1 & 0.22 \\
\hline (B14) & -0.13 & 0.10 & -0.05 & -0.12 & 0.23 & 0.05 & -0.11 & 0.23 & 0.22 & -0.13 & -0.02 & -0.18 & -0.1 & 1.00 & 0.06 \\
\hline (B15) & 0.08 & 0.16 & 0.12 & $0.35^{* *}$ & 0.07 & 0.18 & 0.1 & $0.5^{* * *}$ & 0.04 & 0.10 & $0.33 * *$ & $0.33 * *$ & 0.22 & 0.06 & 1.00 \\
\hline
\end{tabular}

Table B.1: Correlations between Tariff Criteria

This table shows Kendall's rank correlation coefficient for each pair of the criteria (B1) to (B15). *** indicates significance at the $1 \%$-level, ** significance at the $5 \%$-level, and * significance at the $10 \%$-level.

\begin{tabular}{|c|c|c|c|c|c|c|c|c|c|c|}
\hline & (C1) & (C2) & (C3) & (C4) & (C5) & (C6) & (C7) & (C8) & (C9) & (C10) \\
\hline (C1) & 1.00 & 0.24 & $0.45^{* *}$ & 0.12 & $0.34^{*}$ & 0.15 & 0.12 & -0.1 & -0.21 & -0.06 \\
\hline (C2) & 0.24 & 1.00 & $0.42 * *$ & 0.21 & 0.31 & 0.02 & 0.16 & 0.22 & -0.16 & -0.06 \\
\hline (C3) & $0.45^{* *}$ & $0.42 * *$ & 1.00 & 0.09 & 0.29 & -0.03 & -0.02 & -0.03 & -0.27 & 0.02 \\
\hline (C4) & 0.12 & 0.21 & 0.09 & 1.00 & 0.24 & $0.59^{* * *}$ & $0.58^{* * *}$ & 0.17 & 0.13 & 0.13 \\
\hline (C5) & $0.34^{*}$ & 0.31 & 0.29 & 0.24 & 1.00 & $0.44 * *$ & 0.08 & 0.15 & 0.00 & -0.22 \\
\hline (C6) & 0.15 & 0.02 & -0.03 & $0.59^{* * *}$ & $0.44 * *$ & 1.00 & $0.57 * * *$ & 0.18 & $0.32 *$ & 0.14 \\
\hline (C7) & 0.12 & 0.16 & -0.02 & $0.58 * * *$ & 0.08 & $0.57^{* * *}$ & 1.00 & 0.16 & 0.28 & 0.19 \\
\hline (C8) & -0.1 & 0.22 & -0.03 & 0.17 & 0.15 & 0.18 & 0.16 & 1.00 & 0.22 & $0.36^{*}$ \\
\hline (C9) & -0.21 & -0.16 & -0.27 & 0.13 & 0.00 & $0.32 *$ & 0.28 & 0.22 & 1.00 & $0.67^{* * *}$ \\
\hline (C10) & -0.06 & -0.06 & 0.02 & 0.13 & -0.22 & 0.14 & 0.19 & $0.36^{*}$ & $0.67^{* * *}$ & 1.00 \\
\hline
\end{tabular}

Table B.2: Correlations between Pricing Tools

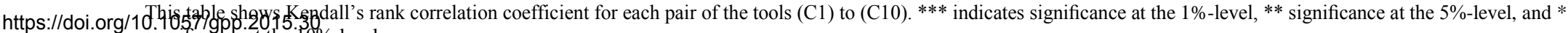


Laas, D., Schmeiser, H. \& Wagner, J. Geneva Pap Risk Insur Issues Pract 41, 398-431 (2016).

\begin{tabular}{|c|c|c|c|c|c|c|c|c|c|c|c|c|c|c|c|}
\hline & (D1) & (D2) & (D3) & (D4) & (D5) & (D6) & (D7) & (D8) & (D9) & (D10) & (D11) & (D12) & (D13) & (D14) & (D15) \\
\hline (D1) & 1.00 & 0.25 & $0.37 * *$ & -0.10 & 0.05 & 0.2 & 0.26 & 0.14 & 0.15 & -0.11 & 0.18 & 0.13 & $0.29 *$ & $0.37^{* *}$ & $0.55^{* * *}$ \\
\hline (D2) & 0.25 & 1.00 & $0.46^{* * *}$ & 0.09 & -0.05 & -0.16 & 0.07 & -0.17 & 0.09 & -0.12 & 0.29 & -0.07 & 0.26 & 0.10 & $0.33^{*}$ \\
\hline (D4) & -0.10 & 0.09 & -0.04 & 1.00 & -0.08 & -0.22 & $-0.41^{* *}$ & 0.22 & 0.21 & 0.21 & 0.24 & 0.27 & 0.27 & 0.13 & 0.22 \\
\hline (D5) & 0.05 & -0.05 & 0.05 & -0.08 & 1.00 & $0.57^{* * *}$ & $0.45^{* *}$ & $0.65^{* * *}$ & $0.43^{* *}$ & $0.66^{* * *}$ & -0.01 & $0.49 * * *$ & 0.21 & 0.03 & 0.14 \\
\hline (D6) & 0.2 & -0.16 & 0.03 & -0.22 & $0.57 * * *$ & 1.00 & $0.44^{* *}$ & $0.48^{* *}$ & 0.3 & 0.19 & 0.17 & $0.43^{* *}$ & 0.03 & 0.23 & 0.11 \\
\hline (D8) & 0.14 & -0.17 & -0.01 & 0.22 & $0.65^{* * *}$ & $0.48^{* *}$ & 0.19 & 1.00 & $0.43^{* *}$ & $0.72 * * *$ & 0.22 & $0.8^{* * *}$ & $0.4 * *$ & 0.12 & $0.3^{*}$ \\
\hline (D9) & 0.15 & 0.09 & 0.25 & 0.21 & $0.43^{* *}$ & 0.3 & 0.12 & $0.43^{* *}$ & 1.00 & $0.33^{*}$ & $0.31^{*}$ & $0.38 * *$ & $0.42 * *$ & 0.18 & $0.3^{*}$ \\
\hline (D10) & -0.11 & -0.12 & -0.27 & 0.21 & $0.66^{* * *}$ & 0.19 & 0.13 & $0.72^{* * *}$ & $0.33 *$ & 1.00 & 0.09 & $0.59 * * *$ & $0.52 * * *$ & -0.04 & 0.21 \\
\hline (D11) & 0.18 & 0.29 & 0.06 & 0.24 & -0.01 & 0.17 & -0.24 & 0.22 & $0.31^{*}$ & 0.09 & 1.00 & $0.37 * *$ & $0.35^{*}$ & 0.24 & $0.34 *$ \\
\hline (D12) & 0.13 & -0.07 & 0.04 & 0.27 & $0.49 * * *$ & $0.43^{* *}$ & 0.15 & $0.8^{* * *}$ & $0.38 * *$ & $0.59 * * *$ & $0.37^{* *}$ & 1.00 & $0.38 * *$ & $0.43 * *$ & 0.23 \\
\hline (D13) & $0.29 *$ & 0.26 & 0.06 & 0.27 & 0.21 & 0.03 & 0.3 & $0.4^{* *}$ & $0.42 * *$ & $0.52^{* * *}$ & $0.35^{*}$ & $0.38 * *$ & 1.00 & 0.22 & $0.47^{* * *}$ \\
\hline (D14) & $0.37 * *$ & 0.10 & 0.17 & 0.13 & 0.03 & 0.23 & $0.37 * *$ & 0.12 & 0.18 & -0.04 & 0.24 & $0.43^{* *}$ & 0.22 & 1.00 & 0.14 \\
\hline
\end{tabular}

Table B.3: Correlations between Characteristics for Customer Valuation

This table shows Kendall's rank correlation coefficient for each pair of the characteristics (D1) to (D15). *** indicates significance at the $1 \%$-level, $* *$ significance at the $5 \%$ level, and * significance at the $10 \%$-level. 